
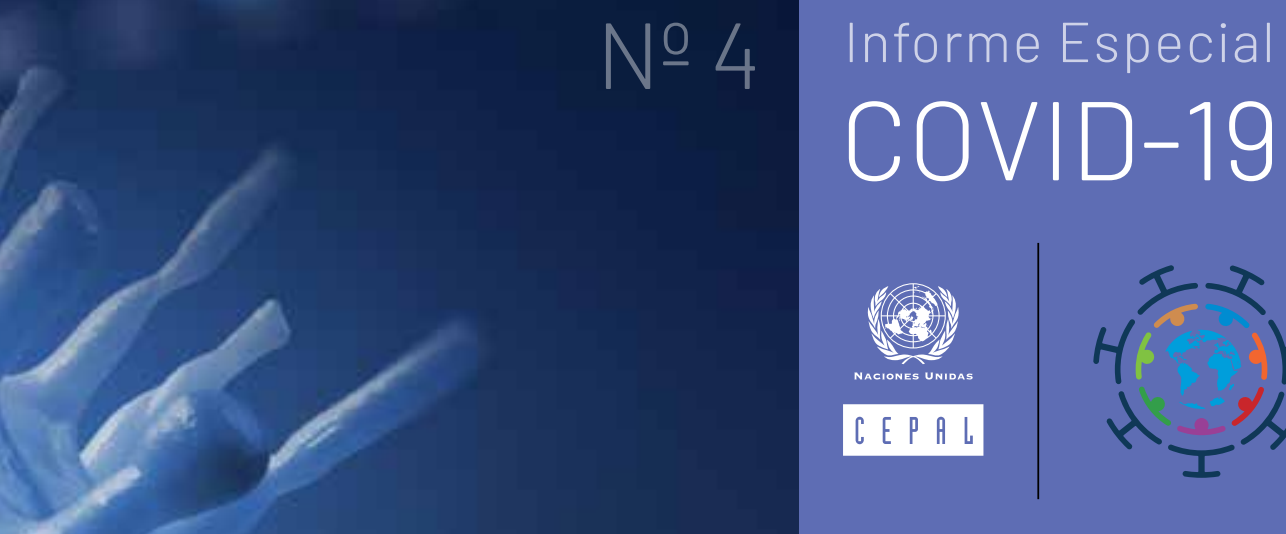

2 de julio de 2020

\title{
Sectores y empresas frente al COVID-19:
} emergencia y reactivación

\section{A. La crisis golpea una estructura productiva y empresarial con debilidades acumuladas por décadas ${ }^{1}$}

- La crisis económica generada por la enfermedad del coronavirus (COVID-19) tiene un impacto importante en los países de América Latina y el Caribe y golpea una estructura productiva y empresarial con debilidades que se han originado a lo largo de décadas.

- La estructura productiva de la región presenta una gran heterogeneidad entre los sectores y entre las empresas. Pocas actividades de producción y procesamiento de recursos naturales, algunos servicios de alta intensidad de capital (electricidad, telecomunicaciones y bancos) y pocas grandes empresas tienen altos niveles de valor agregado por trabajador, mientras que los demás alcanzan niveles muy bajos de productividad.

- Esta estructura productiva es la base de las brechas externa e interna de productividad de la región (CEPAL, 2010). La primera mide la diferencia entre la productividad laboral de América Latina y la de los Estados Unidos, que se adopta como referencia de la frontera tecnológica internacional. La segunda registra la diferencia que existe, dentro de cada país, entre la productividad laboral de las microempresas y pequeñas y medianas empresas (mipymes) y la de las grandes empresas.

- En cuanto a la brecha externa, en 1980 la productividad laboral latinoamericana alcanzaba el $36,6 \%$ de la de los Estados Unidos. Después de una abrupta caída en esa década $y$, en menor medida, en los años noventa, la productividad relativa de la región llegó a ser de apenas un quinto de la de los Estados Unidos entre 1999 y 2018. En términos absolutos, la productividad laboral de la región creció un 0,6\% anual entre 2008 y 2018 (véase el gráfico 1).

\section{Índice}

A. La crisis golpea una estructura productiva y empresarial con debilidades acumuladas por décadas.

B. Más de un tercio del empleo formal y un cuarto del PIB se generan en sectores fuertemente golpeados por la crisis.

C. El impacto en la industria conduciría a un cambio estructural regresivo.

D. Cerrarían 2,7 millones de empresas..............6

E. Las medidas adoptadas: importantes pero insuficientes

F. El rol articulador de las cámaras empresariales

G. Ante la difícil coyuntura empresarial, respuestas a gran escala.

H. De la emergencia a la reactivación: modificación de la estructura productiva y la inserción internacional.

Bibliografía .23

Anexo 
Gráfico 1 | América Latina y el Caribe (27 países): productividad relativa con respecto a la de los Estados Unidos, 1980-2018 (En porcentajes)

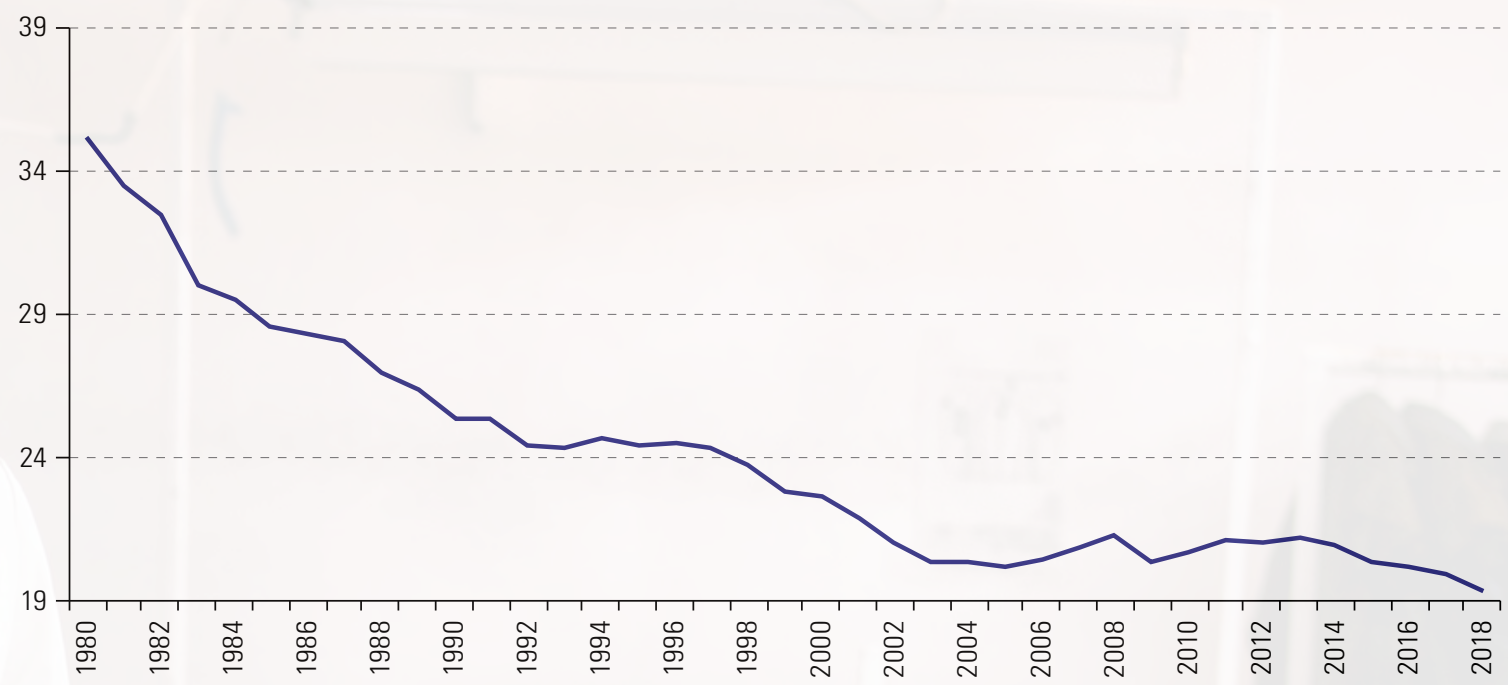

Fuente: Comisión Económica para América Latina y el Caribe (CEPAL), sobre la base de información oficial.

Nota: La productividad relativa externa se mide por el cociente entre la productividad del trabajo de América Latina y la de los Estados Unidos.

- En cuanto a la brecha interna, la heterogeneidad entre las empresas es muy elevada en América Latina. En 2016 la productividad del trabajo de una empresa mediana era, en promedio, menos de la mitad de la correspondiente a una empresa grande. En las empresas pequeñas la productividad laboral alcanzaba apenas al $23 \%$ de la productividad de una empresa grande y las microempresas presentaban una productividad laboral equivalente a solo un $6 \%$ de la correspondiente a las empresas grandes.

- Además, las diferencias de desempeño entre los distintos segmentos de las mipymes eran mucho más marcadas en América Latina que en estructuras productivas menos heterogéneas, como las de la Unión Europea. Por ejemplo, en la Unión Europea la productividad de las empresas medianas no alcanzaba a duplicar la de las microempresas (como proporción de la productividad de las grandes empresas, eran de un $76 \%$ y un $42 \%$, respectivamente), mientras que en América Latina era más de siete veces mayor (46\%, frente a $6 \%$ ) (véase el gráfico 2 ).

Gráfico 2 | América Latina y Unión Europea: productividad relativa interna, 2016 (En porcentajes)

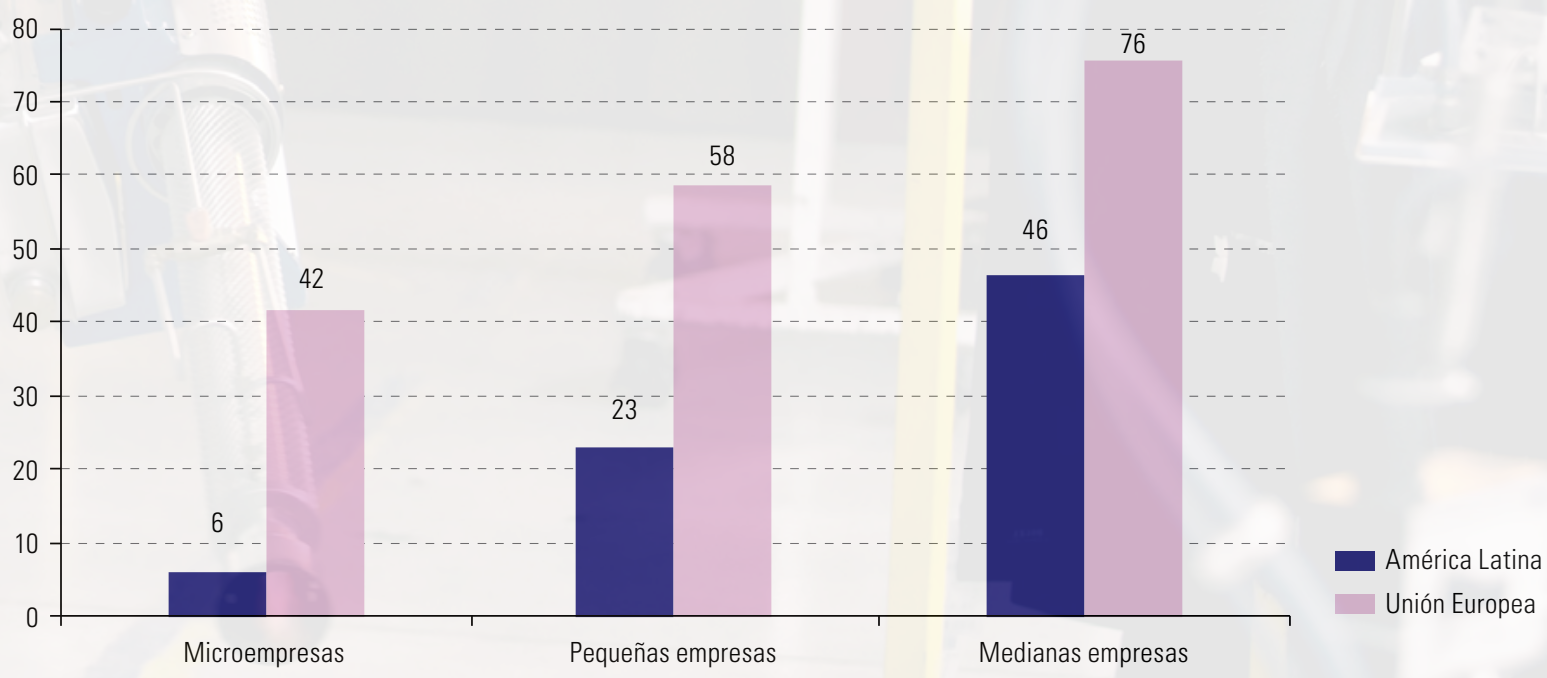

Fuente: Comisión Económica para América Latina y el Caribe (CEPAL), sobre la base de información oficial.

Nota: La productividad relativa interna se mide por el cociente entre el valor de la productividad del trabajo de cada segmento de las mipymes y el valor de la productividad del trabajo de las grandes empresas en un determinado país o región.

- En la estructura productiva de los países de la región, no hay incentivos para el desarrollo de actividades de mayor valor agregado en las mipymes, e incluso hay factores que lo dificultan. En las actividades basadas en recursos naturales y los servicios básicos (agua, luz, electricidad 
y telecomunicaciones), no pueden desarrollarse debido a la elevada intensidad de capital que requieren las inversiones. Por otro lado, las actividades intensivas en conocimientos, cuando existen, son enclaves poco articulados con el resto de la economía en los que son escasas las posibilidades de modernización y mejoramiento para las mipymes que operan en ellos (Dini y Stumpo, 2019). Finalmente, la alta informalidad prevaleciente en muchos mercados laborales (que llega al 54\% del empleo total, según la Organización Internacional del Trabajo (OIT)) dificulta especialmente el desarrollo de las microempresas y las pequeñas empresas.

- Las brechas de productividad interna y externa que caracterizan la estructura productiva de la región son factores que deben ser tenidos en cuenta al diseñar medidas de política para la reactivación que sean conducentes a un cambio estructural progresivo, es decir, que permitan avanzar hacia sectores con mayor productividad y tecnología, generación de empleos y sostenibilidad.

\section{B. Más de un tercio del empleo formal y un cuarto del PIB se generan en sectores fuertemente golpeados por la crisis}

- Es muy difícil prever la intensidad y la duración de la crisis actual. Sin embargo, es posible identificar algunas de sus especificidades.

- Es un fenómeno global, que afecta a todos los países del mundo, aunque con intensidades distintas. En cada economía de la región, se producen consecuencias económicas asociadas a la demanda y la oferta internas, y también a la demanda y la oferta mundiales.

- Como sucedió en otras pandemias, se trata de un virus que era desconocido hasta ahora, para el cual aún no existe vacuna ni remedios universalmente eficaces. La única manera de controlar la pandemia es mediante la prevención que, en general, implica la reducción de los contactos sociales. Las medidas tomadas por los países se traducen en diferentes niveles de restricción social y, por lo tanto, de limitación de las actividades económicas.

- En la medida en que se logre controlar la etapa de mayor difusión del virus, las restricciones sociales y al desarrollo de actividades económicas se modificarán, pero no serán eliminadas del todo.

- Habría tres etapas, vinculadas con las etapas que se vivirán en relación con la epidemia en cada país.

- La primera se relaciona con la emergencia y con las medidas que hay que tomar en un plazo muy corto.

- La segunda se producirá cuando, una vez controlados los focos de esa epidemia, haya que "convivir" con un virus que, sin controles sanitarios y sociales, puede volver a difundirse. Se mantendrán algunas (muchas) de las restricciones a las actividades económicas y sociales y la economía funcionará "a media marcha", con diferencias entre sectores. Esta etapa es la que habitualmente se denomina de reactivación.

- La tercera tendrá lugar cuando no haya peligro de contagio (una vez que exista la vacuna) e implicará una nueva realidad económica y social. Esa realidad será distinta en cada país según la duración e intensidad de las dos primeras etapas, las medidas económicas y sociales que se hayan tomado y las capacidades institucionales, productivas y tecnológicas acumuladas. Además, habrá cambios en el escenario económico y político internacional, puesto que los países entrarán a la segunda y tercera etapas en diferentes momentos y en condiciones distintas.

- La crisis económica tiene su origen tanto en la oferta como en la demanda. Las restricciones sociales han generado la suspensión, total o parcial, de las actividades productivas. Este efecto ha sido más fuerte en sectores cuyas actividades implican aglomeración y cercanía física (turismo, espectáculos, hoteles y restaurantes, transporte y servicios personales), mientras que ha sido menor en aquellos que se han considerado indispensables (alimentos, desinfectantes, artículos de limpieza, medicamentos e insumos y equipos médicos).

- La interrupción de muchas actividades productivas ha generado problemas también en la provisión de insumos, nacionales e importados, para las empresas que han seguido operando.

- Por el lado de la demanda, la reducción de los ingresos de los consumidores y la incertidumbre han redundado en una caída del consumo y un cambio en los patrones de consumo. Esto se ha dado en segmentos de bienes de consumo duradero (automóviles, muebles, electrodomésticos, 
viviendas, prendas y calzado, por ejemplo), al mismo tiempo que el impacto ha sido menor o incluso positivo para las ventas de otros tipos de bienes y servicios (productos de limpieza y desinfectantes, alimentos duraderos, televisión vía Internet y telecomunicaciones).

- La caída de la actividad económica y otros aspectos de la coyuntura internacional (como la abrupta disminución del precio del petróleo en los últimos meses) han ocasionado una reducción generalizada de la demanda externa y de los retornos de las exportaciones.

- La combinación de los efectos sobre la oferta y la demanda ha tenido intensidades distintas en los diferentes sectores (véase el diagrama 1).

Diagrama 1 | Intensidad de los efectos de la crisis, por sector de actividad económica
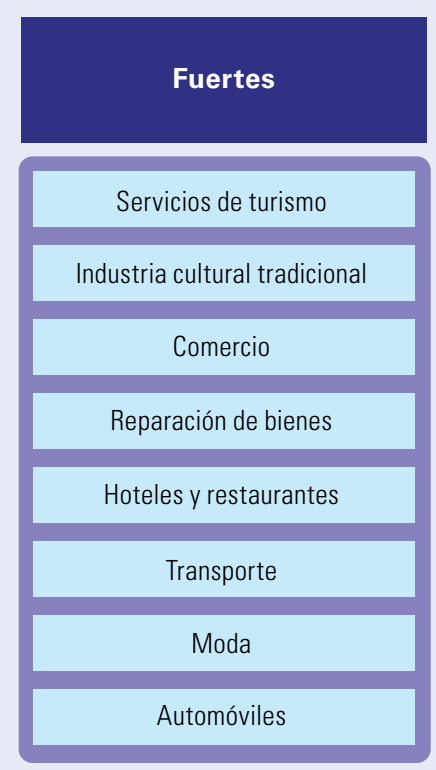
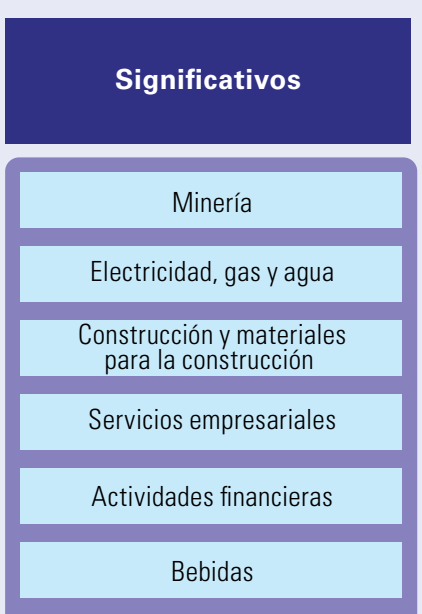

Muebles y madera

Industria química

Electrónica - Maquinaria y equipo
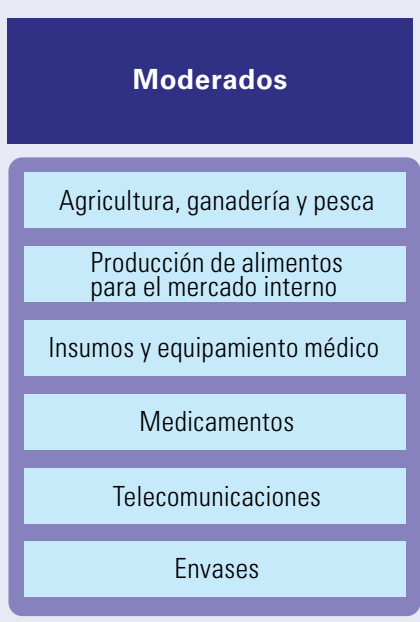

Fuente: Comisión Económica para América Latina y el Caribe (CEPAL).

- Sobre la base de esta clasificación según la intensidad de los efectos de la pandemia, la Comisión Económica para América Latina y el Caribe (CEPAL) estima que un 34,2\% del empleo formal y un $\mathbf{2 4 , 6} \%$ del PIB de la región corresponden a sectores fuertemente afectados por la crisis derivada de la pandemia. Más aún, menos de la quinta parte del empleo y del PIB se generan en sectores que serían afectados solo de forma moderada (véase el gráfico 3).

Gráfico 3 | América Latina y el Caribe (27 países): PIB y empleo correspondientes a los distintos sectores según intensidad del impacto esperado de la crisis (En porcentajes)

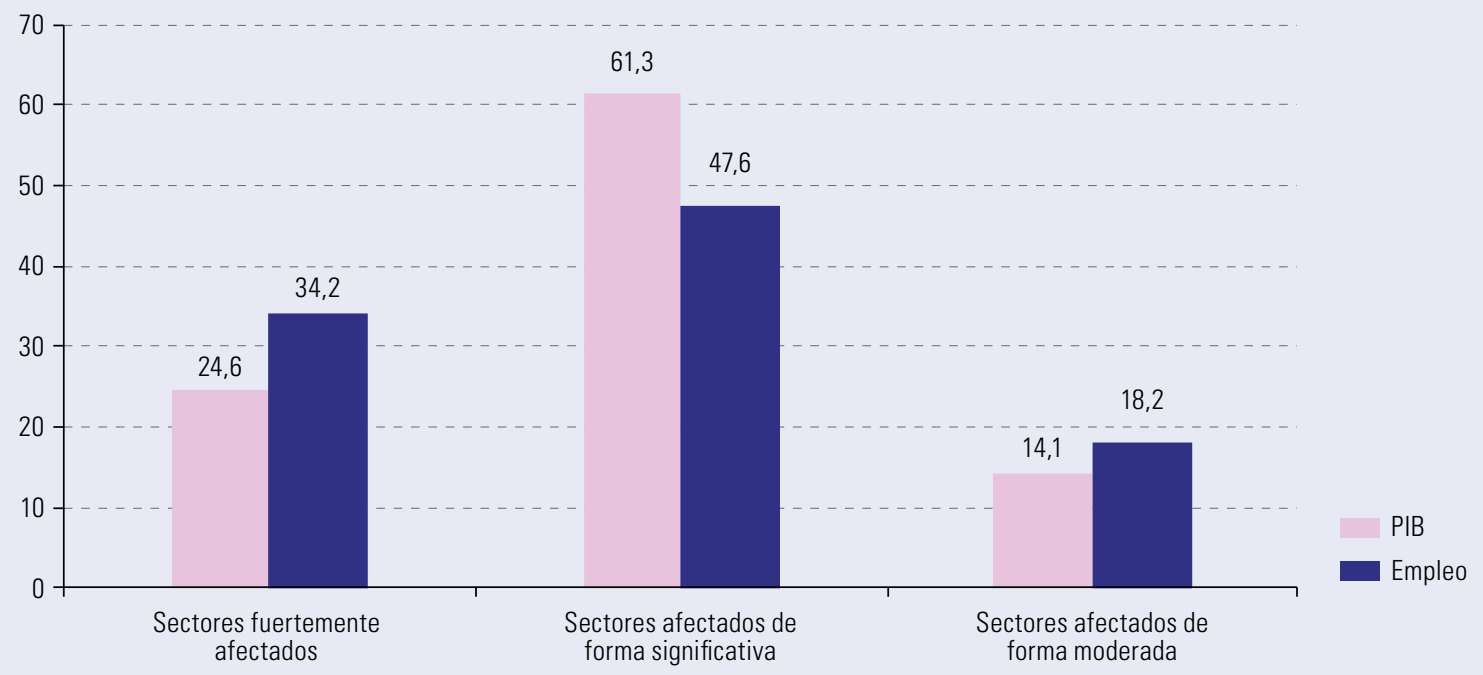

Fuente: Comisión Económica para América Latina y el Caribe (CEPAL), sobre la base de información oficial. 


\section{El impacto en la industria conduciría a un cambio estructural regresivo}

- La industria en su conjunto sufre un impacto significativo; sin embargo, para una parte importante de los sectores intensivos en tecnología y de los intensivos en trabajo² la situación es aún peor (véase el gráfico 4). En particular, el $92 \%$ de las ramas industriales de mayor contenido tecnológico están enfrentando una crisis que puede ser considerada entre fuerte y significativa.

Gráfico 4 | América Latina (8 países): proporción de la producción de los distintos grupos de sectores industriales de acuerdo con la intensidad del impacto esperado de la crisis

(En porcentajes)

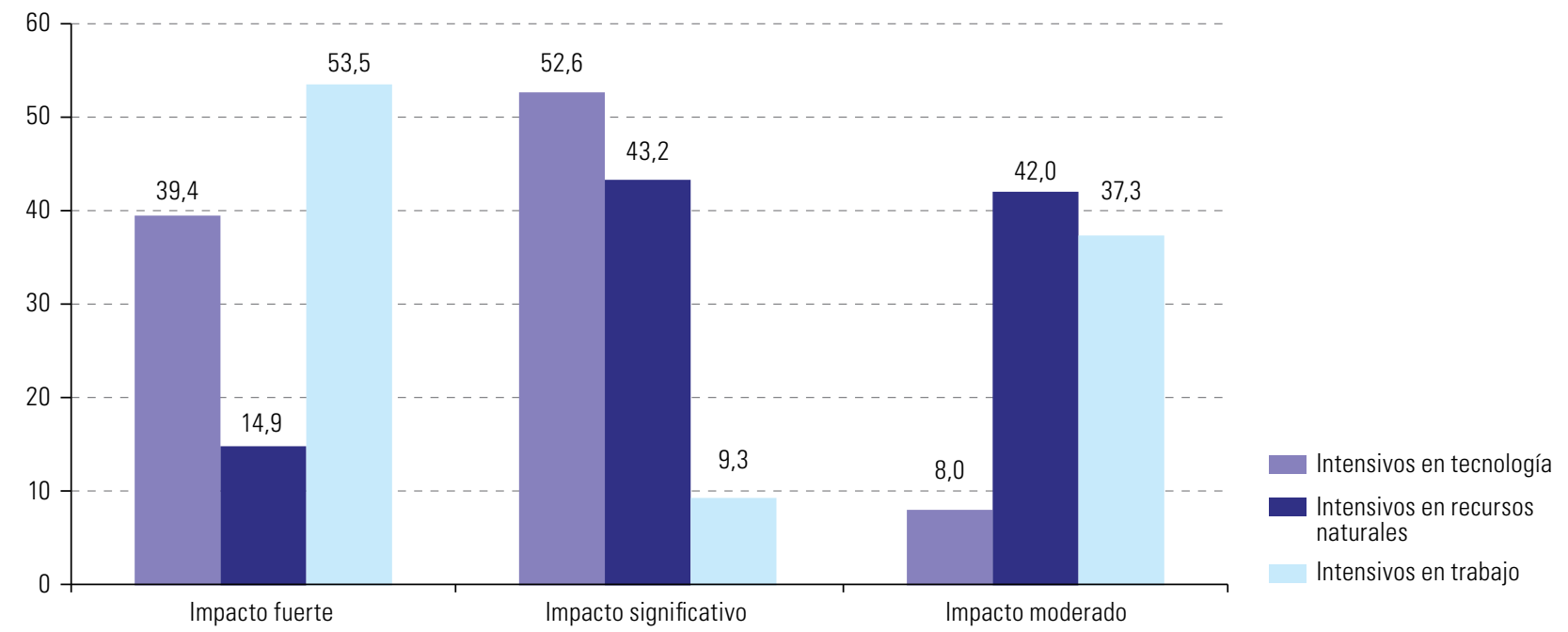

Fuente: Comisión Económica para América Latina y el Caribe (CEPAL), sobre la base de información oficial.

- Estas ramas reúnen las actividades más intensivas en aprendizaje e innovación, que son fundamentales para el proceso de diversificación e incorporación de mayor valor agregado necesario para cerrar las brechas de productividad e ingresar a una senda de crecimiento sostenible de largo plazo.

- En este sentido, la crisis golpea con mayor intensidad a los sectores industriales potencialmente de mayor dinamismo tecnológico y, por lo tanto, profundizará los problemas estructurales de las economías de la región. Esto significa que, si no se implementan políticas adecuadas para fortalecer esas ramas productivas, existe una elevada probabilidad de que se genere un cambio estructural regresivo que conduciría a la reprimarización de las economías de la región.

- El impacto sobre la estructura industrial ya se puede observar en algunos países, al analizar el desempeño del primer cuatrimestre de 2020 comparado con el del mismo período de 2019.

- En el Brasil, la producción industrial cayó un 8,2\%. Sin embargo, la caída ha sido mucho más acentuada en los sectores de autos y autopartes $(-31,1 \%)$ y "otros equipos de transporte" $(-30,7 \%)$, que incluye la industria aeroespacial (Agência IBGE Noticias, 2020).

- En México, en cambio, la actividad de la industria manufacturera se redujo un $10,9 \%$ en los primeros cuatros meses del año y los sectores más afectados han sido los de cuero y calzado $(-29,5 \%)$ y equipo de transporte $(-26,9 \%)$, mientras que la industria de alimentos registró un aumento del 2,5\% (INEGI, 2020).

- En la Argentina, la producción industrial disminuyó un $13,5 \%$ y los sectores de automóviles $(-40,4 \%)$, autopartes $(-37,8 \%)$, motocicletas $(-56,2 \%)$ y equipos eléctricos $(-41,6 \%)$ presentaron resultados aún peores. También algunos sectores intensivos en trabajo sufrieron caídas muy superiores al promedio de la industria; por ejemplo, los sectores de textiles $(-27,4 \%)$, prendas $(-37,7 \%)$ y calzado $(-40,3 \%)$. En cambio, el rubro de alimentos y bebidas creció un 1,5\%.

\footnotetext{
Las actividades industriales han sido agrupadas en tres bloques de sectores a partir de la clasificación propuesta por Katz y Stumpo(2001). En los sectores intensivos en tecnología se ha incluido la producción de autos y autopartes, otros equipos de transporte, electrónica (productos finales y componentes), maquinaria industrial, instrumentos médicos y científicos, y productos farmacéuticos. En las ramas intensivas en recursos naturales se incluyen las actividades de fundición de metales, madera, celulosa y papel, industria química, materiales de construcción, alimentos, bebidas y tabaco. Finalmente, los sectores intensivos en mano de obra reúnen la producción de textiles, prendas, cuero, calzado, productos de plástico y artículos de limpieza.
} 
- En Colombia la caída fue de un $7,7 \%$ para el total de la industria y los peores resultados se dieron en los sectores de cuero y calzado $(-37,8 \%)$ y autos y autopartes $(-36,9 \%)$. También en este caso la industria de alimentos anotó un crecimiento $(6,1 \%)$.

- Aún más grave es la situación en el Perú, donde la producción industrial se redujo un 21,4\% en el primer cuatrimestre y la fabricación de bienes de capital disminuyó un 47,9\%.

- Estos primeros resultados en varias de las mayores economías de la región reafirman la consideración de que los sectores intensivos en tecnología, en su conjunto, serán los más afectados.

\section{Cerrarían 2,7 millones de empresas}

- La gran mayoría de las empresas de la región han registrado importantes caídas de sus ingresos y presentan dificultades para mantener sus actividades: tienen serios problemas para cumplir con sus obligaciones salariales y financieras, y dificultades para acceder a financiamiento para capital de trabajo.

- Hasta la primera semana de junio de 2020, información recopilada por las cámaras empresariales resaltaba que:

- En Colombia, el 96\% de las empresas tuvieron una caída en sus ventas (el 75\% registró una disminución superior al 50\%); el $82 \%$ de las empresas formales podrían subsistir solo entre uno y dos meses con sus propios recursos (CONFECAMARAS, 2020).

- En el Brasil, el 76\% de las empresas industriales redujeron o paralizaron su producción y el $55 \%$ ha tenido dificultades para acceder a crédito para capital de trabajo (CNI, 2020).

- En la Argentina, el 44\% de las empresas industriales no tenían liquidez para pagar el $50 \%$ de los salarios de abril (un 12,3\% no pudo pagar la nómina); el 38\% no pudo pagar servicios públicos; el $48 \%$ no pudo pagar a sus proveedores, y el $57 \%$ no pagó los impuestos (UIA, 2020).

- En Chile, el $37,5 \%$ de las empresas redujeron su personal entre abril y mayo, y el $44 \%$ de las empresas están en un estado financiero malo o crítico, cifra que aumenta al $51 \%$ entre las microempresas (CNC, 2020).

- En el Uruguay, el 59,4\% de las empresas de comercio y servicios han enviado a sus empleados al seguro de desempleo, y destacan entre ellas las empresas de alojamiento y servicios de comida $(81,5 \%)$. Entre las empresas que enviaron empleados al seguro de desempleo, el $41,2 \%$ envió a más del $75 \%$ de la planilla (CNCS, 2020).

- En Panamá, los sectores que registraron las mayores caídas de sus ingresos fueron los de hoteles $(-99,4 \%)$, construcción $(-86,4 \%)$, restaurantes $(-85,0 \%)$, comercio al por menor $(-83,8 \%)$ y servicios turísticos $(-78,7 \%)$ (CCIAP, 2020).

- En Centroamérica, el 50\% de las empresas necesitarían entre cuatro y nueve meses para recuperar el nivel de facturación previo a la crisis. Esta situación se agrava entre las microempresas, que necesitarían un período que va de siete meses a más de un año para lograr este objetivo (FECAMCO, 2020).

- Aunque la crisis afecta a todas las empresas, el impacto será mucho mayor en el caso de las microempresas y las pymes, por su peso en la estructura empresarial de la región (véase el gráfico 5), en que se traducirá en grandes cierres de empresas y pérdidas de puestos de trabajo.

- Sobre la base de los diagnósticos de las cámaras empresariales en relación con la situación de las mipymes y de las características de la crisis, la CEPAL estima que cerrarían más de 2,7 millones de empresas formales en la región, con una pérdida de $\mathbf{8 , 5}$ millones de puestos de trabajo, sin incluir las reducciones de empleos que realicen las empresas que seguirán operando (véanse los gráficos $6,7,8$ y 9).

- El impacto será muy diferente según el sector y el tipo de empresa. Varios de los sectores fuertemente afectados, como el comercio y los hoteles y restaurantes, cuentan con gran cantidad de microempresas y pequeñas empresas, que serán las más afectadas (véase el gráfico 7). 
Gráfico 5 || América Latina (8 países): distribución de las empresas y participación en el empleo, según tamaño, 2016 (En porcentajes)

\section{A. Distribución del número de empresas}

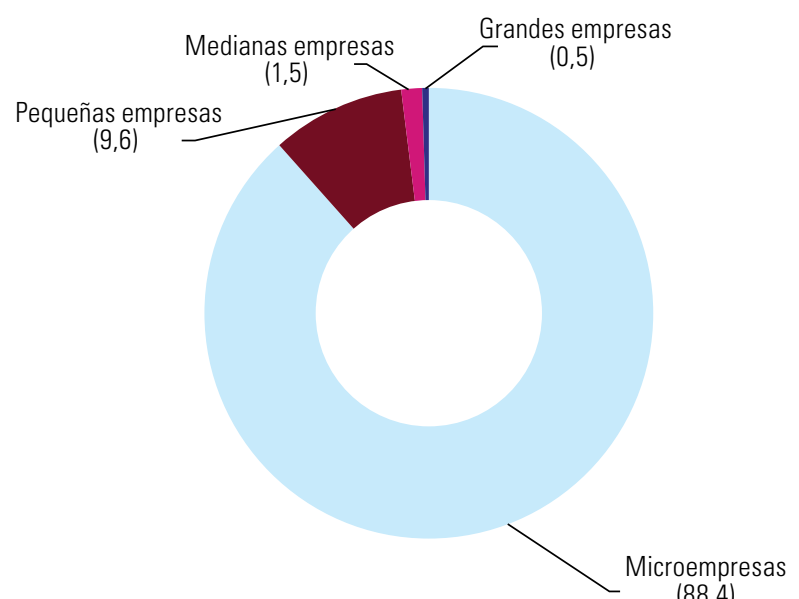

\section{B. Participación en el empleo}

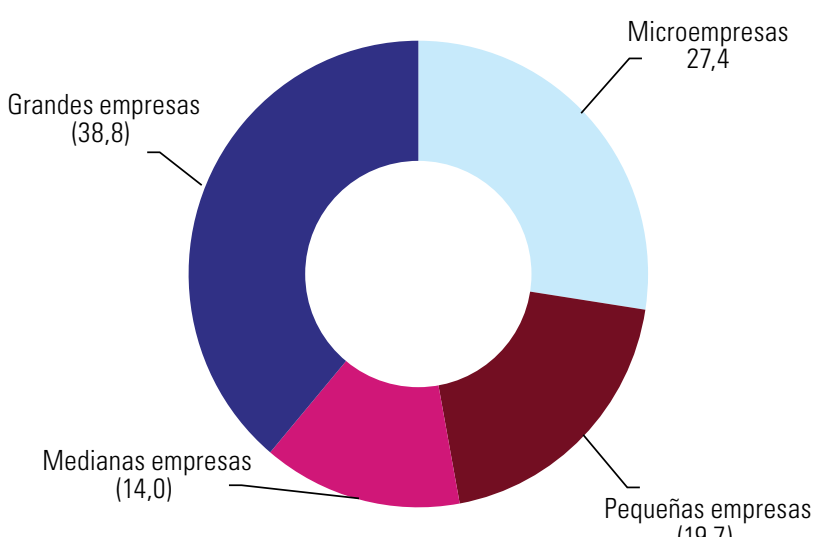

Fuente: Comisión Económica para América Latina y el Caribe (CEPAL), sobre la base de información oficial.

Gráfico 6 | América Latina y el Caribe (27 países): empresas que podrían cerrar como consecuencia de la crisis, según tamaño (En número y porcentajes)

A. Número

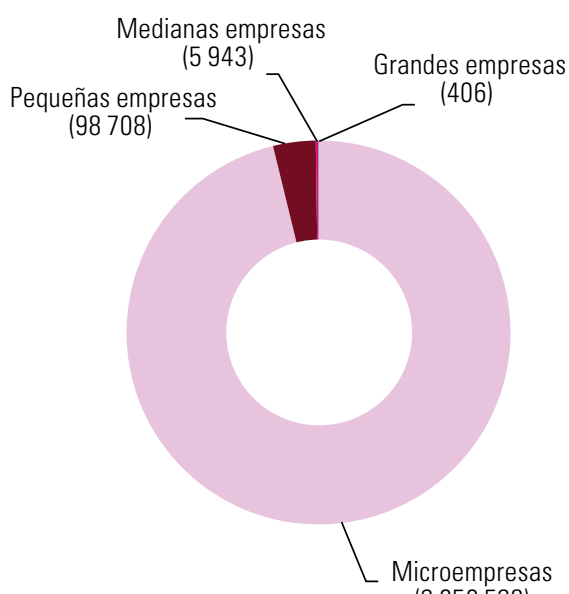

\section{B. Porcentajes ${ }^{\mathrm{a}}$}

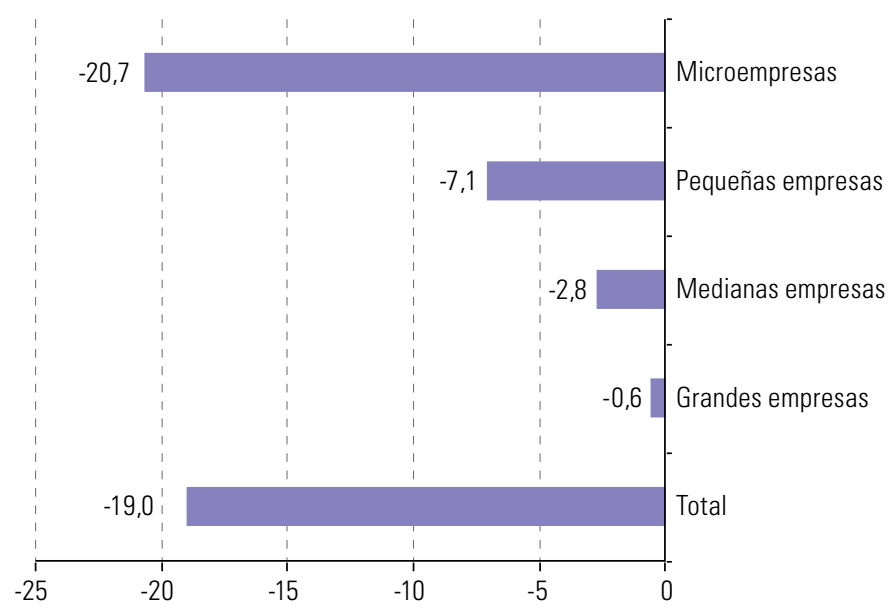

Fuente: Comisión Económica para América Latina y el Caribe (CEPAL), sobre la base de información oficial.

a Los porcentajes se expresan en cifras negativas para destacar que se trata de una disminución del número de empresas de cada categoría.

Gráfico 7 | América Latina y el Caribe (27 países): empresas que podrían cerrar como consecuencia de la crisis, según sector (En número)

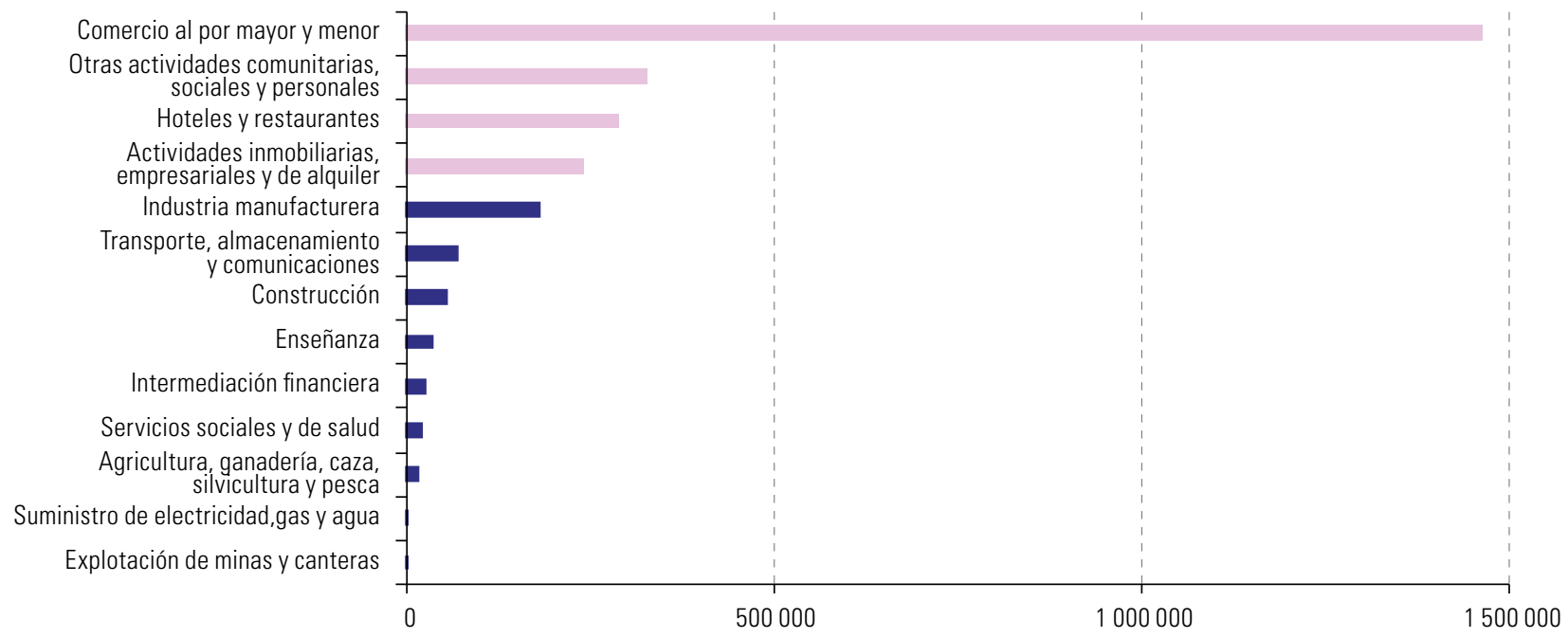

Fuente: Comisión Económica para América Latina y el Caribe (CEPAL), sobre la base de información oficial. 
Gráfico 8 | América Latina y el Caribe (27 países): empleos que podrían perderse por cierres de empresas como consecuencia de la crisis, según sector

(En número de trabajadores)

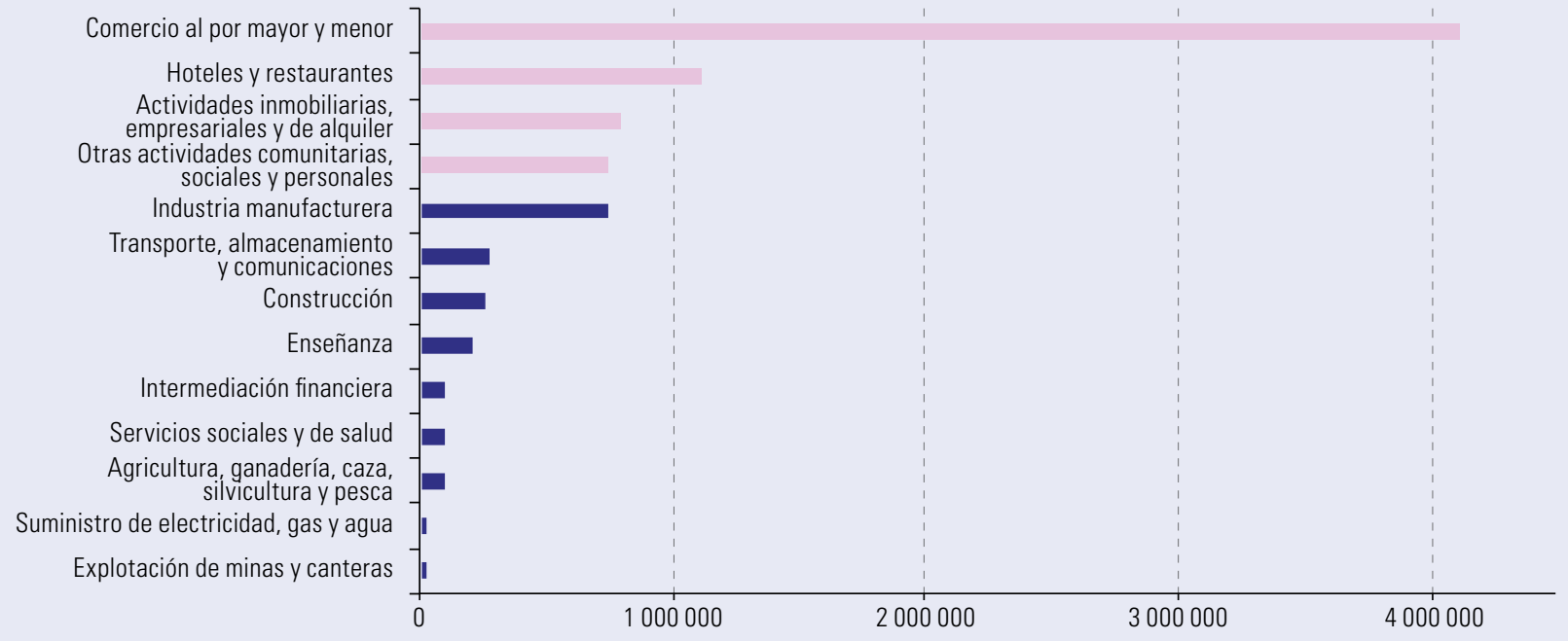

Fuente: Comisión Económica para América Latina y el Caribe (CEPAL), sobre la base de información oficial.

Gráfico 9 | América Latina y el Caribe (27 países): empleos que podrían perderse por cierres de empresas como consecuencia de la crisis, según tamaño de la empresa (En número de trabajadores y porcentajes)

A. Número de trabajadores

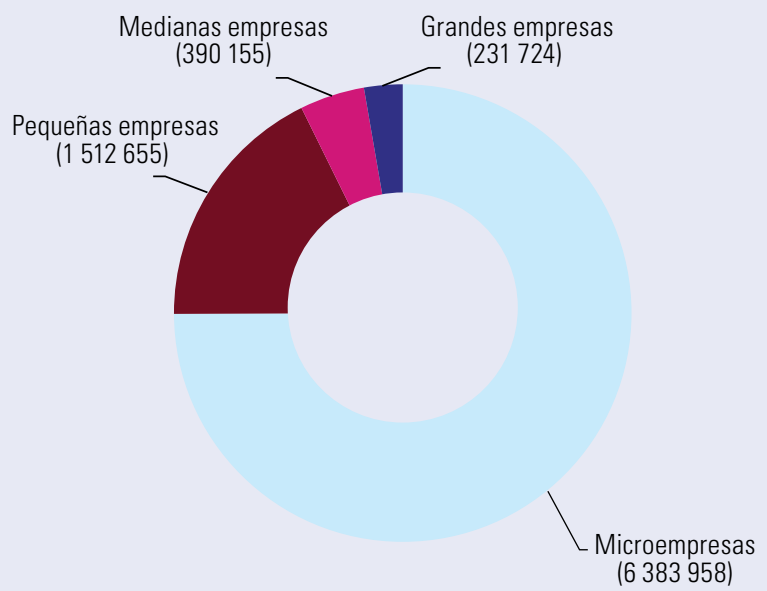

B. Porcentajes ${ }^{a}$

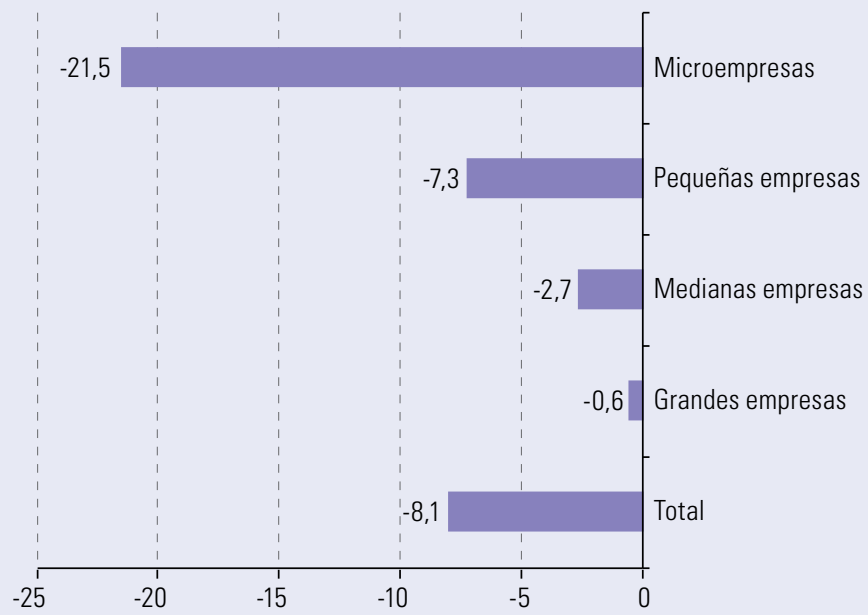

Fuente: Comisión Económica para América Latina y el Caribe (CEPAL), sobre la base de información oficial.

a Los porcentajes se expresan en cifras negativas para destacar que se trata de una disminución de la cantidad de ocupados en cada categoría de empresas.

\section{E. Las medidas adoptadas: importantes pero insuficientes}

- Un objetivo inmediato de los gobiernos ha sido reducir la destrucción de capacidades provocada en la fase crítica de la pandemia. Esta destrucción de capacidades (despidos y cierres de empresas) dificulta la recuperación de la actividad de las economías una vez pasada la emergencia.

- El cierre de empresas destruye el saber empresarial y el capital físico localizado, así como cadenas productivas completas y circuitos de flujo de pagos. La imposibilidad de los agentes económicos de adaptarse a los cambios bruscos del entorno tiene efectos localizados y sistémicos, y se inician procesos de histéresis en que dichos agentes mantienen su comportamiento en el tiempo más allá de la crisis, prolongando así sus efectos.

- A partir de marzo de 2020, para sostener la estructura productiva y evitar la destrucción de capacidades en lasempresas, los gobiernos anunciaron un conjunto ampliode medidas. LaCEPAL ha identificado $\mathbf{3 5 1}$ medidas, agrupadas en seis categorías según sus objetivos. En 19 países, 
91 de estas medidas tuvieron un enfoque sectorial y se orientaron a problemas específicos de ramas productivas determinadas.

- Proveer liquidez y mejorar el acceso al crédito fueron las políticas más frecuentes. A continuación, se muestran las medidas anunciadas de ayuda directa y las que buscan impedir despidos en las empresas formales (véanse el cuadro 1 y el gráfico 10) ${ }^{3}$.

Cuadro 1 | América Latina y el Caribe: número de países con anuncios de medidas, según objetivo

\begin{tabular}{llc}
\hline Objetivo & & Países \\
\hline Liquidez & $\begin{array}{l}\text { Mantener el flujo de pagos en el corto plazo mediante la postergación de } \\
\text { pagos y renegociaciones }\end{array}$ & 24 \\
\hline Crédito & $\begin{array}{l}\text { Aumentar la disponibilidad de recursos para créditos, fondos para } \\
\text { garantías y flexibilización de las condiciones de acceso a ellos }\end{array}$ & 22 \\
\hline Ayuda directa & $\begin{array}{l}\text { Realizar transferencias de fondos (subsidios) o cancelar obligaciones } \\
\text { (se incluyen medidas para trabajadores independientes formales) }\end{array}$ & 22 \\
\hline Protección del empleo & $\begin{array}{l}\text { Evitar despidos mediante subsidios a salarios y aportes patronales, } \\
\text { suspensión de salarios y reducción de jornadas y flexibilización laboral } \\
\text { (se excluyen medidas para el fomento y la regulación del teletrabajo) }\end{array}$ & 18 \\
\hline Apoyo a la producción & $\begin{array}{l}\text { Fomentar la producción interna de bienes y servicios esenciales } \\
\text { en la emergencia(se incluyen medidas de compras públicas) }\end{array}$ & 12 \\
\hline Exportaciones & Fomentar la actividad exportadora & 5 \\
\hline
\end{tabular}

Fuente: Comisión Económica para América Latina y el Caribe (CEPAL), sobre la base de Observatorio COVID-19 en América Latina y el Caribe [en línea] https://www.cepal.org/es/temas/covid-19 e información oficial al 27 de mayo de 2020.

Gráfico 10 | América Latina y el Caribe (27 países): medidas adoptadas en los países según objetivos, por subregión (En porcentajes del número de medidas)

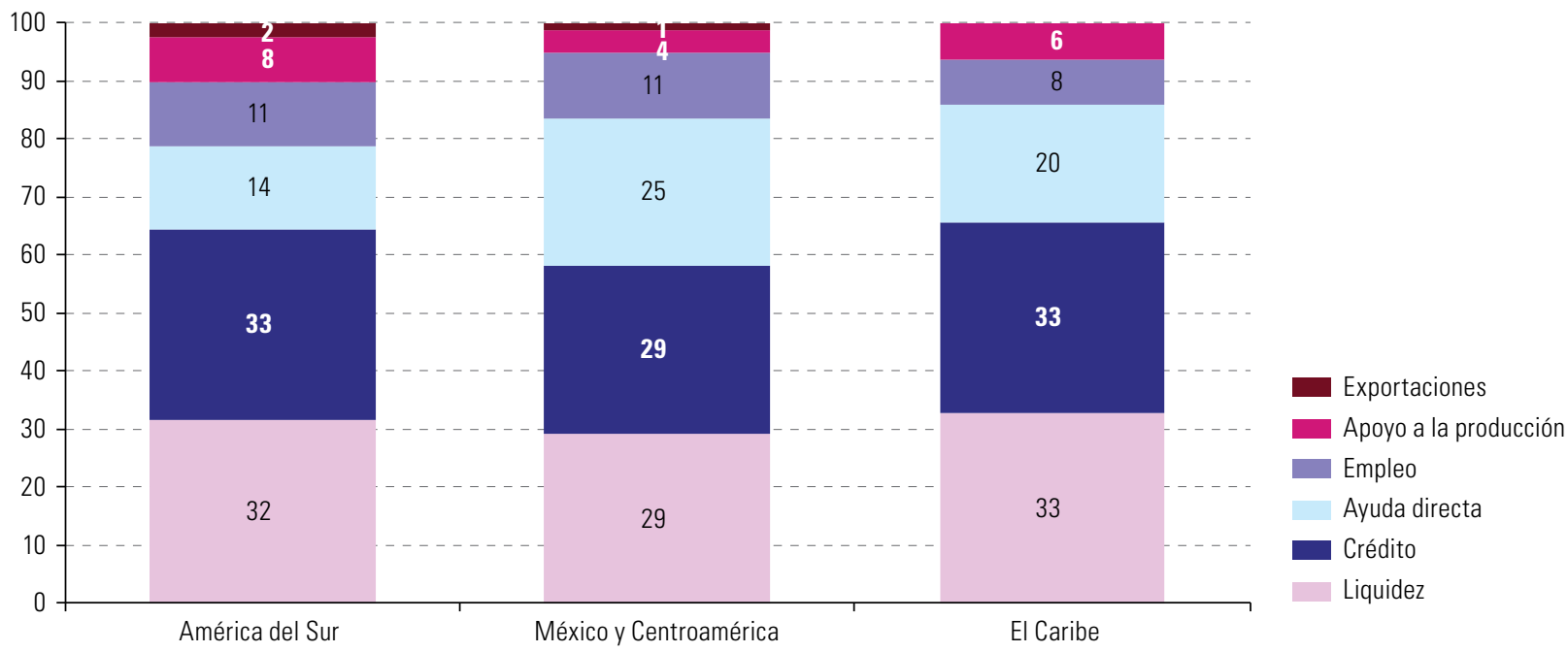

Fuente: Comisión Económica para América Latina y el Caribe (CEPAL), sobre la base de Observatorio COVID-19 en América Latina y el Caribe [en línea] https://www.cepal.org/es/temas/covid-19 e información oficial al 27 de mayo de 2020.

- Para aumentar la disponibilidad de crédito, el $71 \%$ de las medidas suponen una mayor asignación de recursos por parte del Estado, por ejemplo mediante líneas de crédito o fondos para garantías, mientras que cerca de una tercera parte de ellas implica cambios en la regulación para inyectar más liquidez. Los recursos provienen generalmente del tesoro público y, en pocos casos, de fondos de la seguridad social y de préstamos de instituciones internacionales. Entre las medidas anunciadas que no requieren fondos adicionales se encuentran la reducción de encajes legales, la disminución de las tasas de interés a instituciones financieras privadas (bancos, cooperativas de crédito, cajas de ahorro, instituciones de microfinanzas) o la simplificación de trámites y requisitos de acceso a los créditos.

\footnotetext{
Las medidas relevadas corresponden solo a las que buscan evitar los despidos y sostener el empleo formal, sin incluir las medidas para mitigar el impacto de la emergencia en los desempleados y los trabajadores informales. No se incluyen las recomendaciones de los gobiernos de adoptar, de manera voluntaria y consensuada con los trabajadores, modalidades de teletrabajo o trabajo desde el hogar, ni la regulación de este tipo de trabajo. Tales recomendaciones se dieron en casi todos los países, pero alcanzan solo a una fracción de las actividades productivas (las susceptibles de adoptar una modalidad de teletrabajo), al tiempo que no todos los trabajadores cuentan con las condiciones materiales y las habilidades para realizar este tipo de actividades.
} 
- Los medios utilizados dependen de las instituciones bancarias de cada país. La mayoría de los países se apoyaron en instituciones y bancos públicos para otorgar créditos de forma directa. Los bancos de desarrollo han tenido un papel relevante, entre ellos, el Banco de la Nación Argentina, la Caja Económica Federal y el Banco Nacional de Desarrollo Económico y Social (BNDES) en el Brasil, el Banco Estado en Chile, Bancoldex en Colombia y el Banco del Instituto Ecuatoriano de Seguridad Social (BIESS). La disposición de fondos públicos como garantía para los créditos ha sido una de las modalidades más extendidas.

- En conjunto, el monto comprendido por las medidas de crédito anunciadas en 19 países representa el 3,9\% del PIB de la región en 2019. Las medidas de crédito son la herramienta en la cual los gobiernos han comprometido más recursos, aunque el panorama es heterogéneo entre países. En la mayoría, los fondos correspondientes a las medidas para impulsar el crédito tienen un peso menor al $4 \%$ del PIB (véase el gráfico 11).

Gráfico 11 América Latina y el Caribe (19 países): monto anunciado para medidas en materia de crédito, por país (En porcentajes del PIB de 2019)

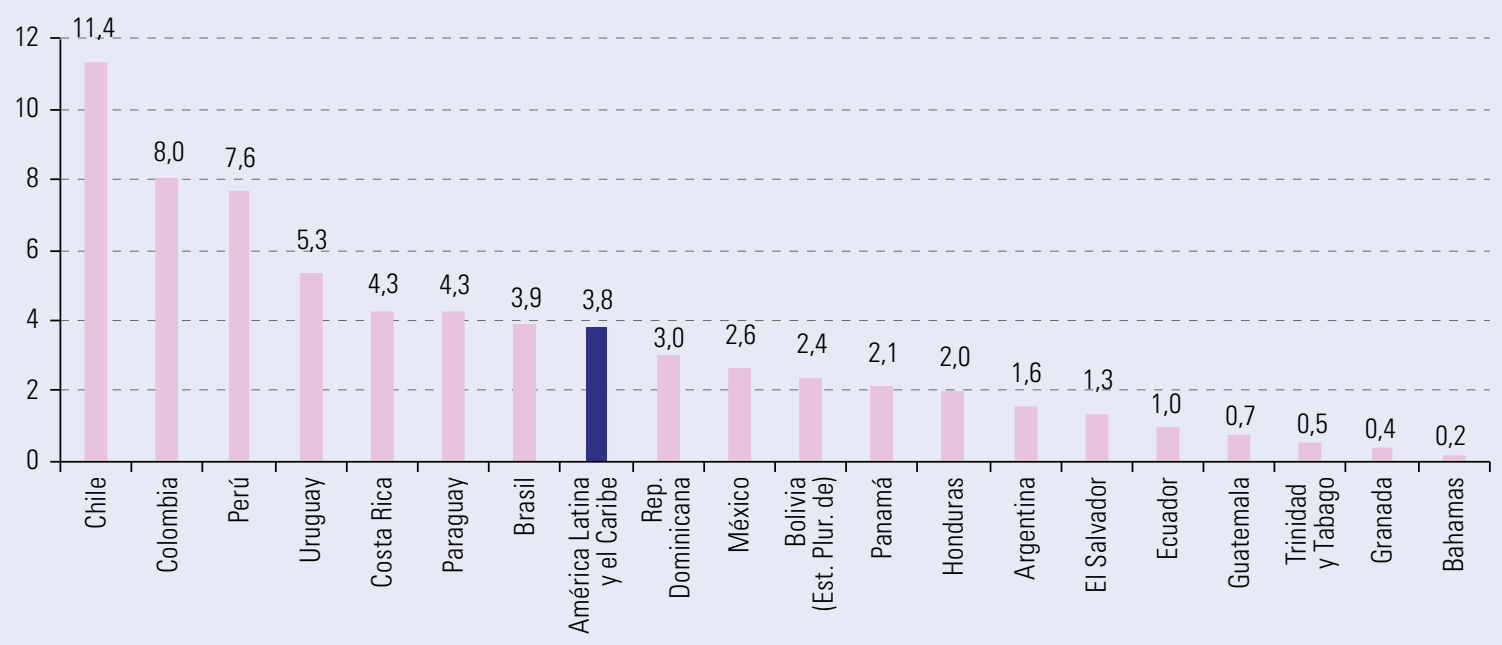

Fuente: Comisión Económica para América Latina y el Caribe (CEPAL), sobre la base de Observatorio COVID-19 en América Latina y el Caribe [en línea] https://www.cepal.org/es/temas/covid-19 e información oficial al 27 de mayo de 2020.

Nota: La estimación incluye las medidas respecto de las que se logró identificar el monto (71\% del total de medidas de crédito comunicadas por los países).

- En casi todos los países se anunciaron líneas de crédito especiales para financiar el capital de trabajo de las mipymes de modo que continuaran sus actividades y pagaran sus nóminas. En muchos casos, estas medidas se han dirigido a los sectores más afectados, como el del turismo, o hacia sectores estratégicos para la seguridad alimentaria, como el agropecuario.

- Las características de los créditos varían según el país y en la gran mayoría de los casos son programas nuevos. Los plazos de pago van desde uno a cinco años y en la mitad de los casos se proponen plazos de tres años (se identificaron los plazos en un $25 \%$ de las medidas anunciadas). Las tasas de interés han sido reducidas, subsidiadas en muchos casos, llegando incluso al $0 \%$ real; los períodos de gracia observados varían entre 3 y 12 meses. Por su parte, los montos solicitados se ajustan al nivel de ventas de cada empresa, en algunos casos con máximos definidos. En algunos países, se anunciaron condiciones más favorables para inversiones productivas y se establecieron programas supeditados a que las empresas no despidan trabajadores.

- Un segundo grupo de medidas frecuentes busca proveer liquidez a las empresas y evitar que se interrumpa el flujo de pagos en la economía. La postergación del pago de obligaciones con el Estado y con entidades financieras fueron las herramientas más utilizadas (véase el gráfico 12). Para permitir la reprogramación, reestructuración y renegociación de los créditos privados, muchos países modificaron la regulación bancaria, con medidas como la admisión de mayores niveles de endeudamiento y moratorias, la mantención de la clasificación de riesgo de los deudores, el incremento de los plazos de las garantías públicas, el desembolso de recursos públicos para la reprogramación de deudas y la refinanciación de créditos, y la asesoría pública a las empresas para la renegociación de créditos. Entre las condiciones que se busca modificar se 
encuentran los costos de apertura, las tasas de interés, los plazos de pago y los montos de las cuotas. Las microempresas y las empresas de menor tamaño han tenido un trato preferencial.

Gráfico 12 | América Latina y el Caribe (24 países): medidas para proveer liquidez, según el mecanismo empleado (En porcentajes del número de medidas)

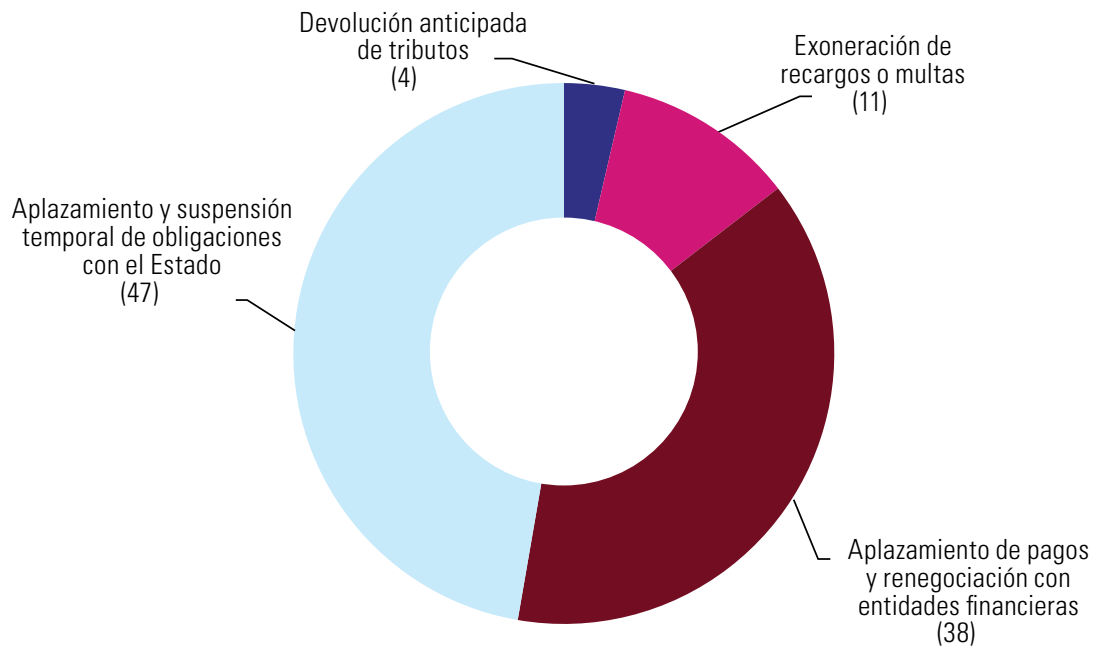

Fuente: Comisión Económica para América Latina y el Caribe (CEPAL), sobre la base de Observatorio COVID-19 en América Latina y el Caribe [en línea] https://www.cepal.org/es/temas/covid-19 e información oficial al 27 de mayo de 2020.

n Sin embargo, el $86 \%$ de estas medidas contemplan horizontes temporales inferiores a seis meses, lo que, si bien supone un esfuerzo financiero considerable (en el Brasil, por ejemplo, el monto asociado a medidas de liquidez representa el 3,1\% del PIB), no sería suficiente para que el sector empresarial enfrente una recuperación que, muy probablemente, será lenta y gradual (véase el gráfico 13).

Gráfico 13 | América Latina y el Caribe (24 países): horizonte temporal de las medidas para proveer liquidez (En porcentajes del número de medidas)

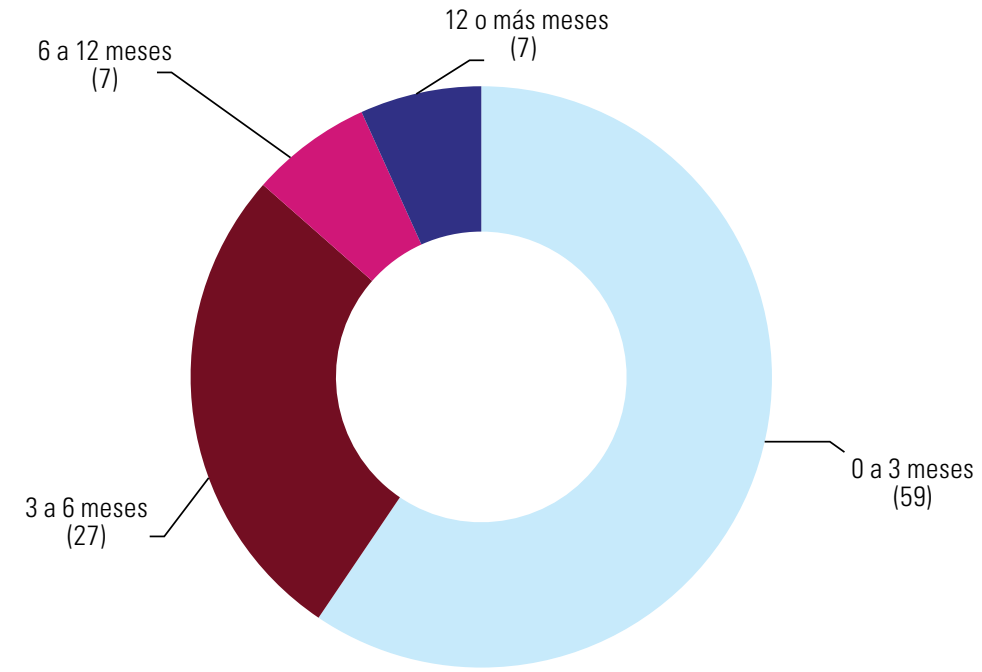

Fuente: Comisión Económica para América Latina y el Caribe (CEPAL), sobre la base de Observatorio COVID-19 en América Latina y el Caribe [en línea] https://www.cepal.org/es/temas/covid-19 e información oficial al 27 de mayo de 2020.

Nota: Incluye solo las medidas respecto de las que se logró identificar el plazo (el 67\% del total de medidas de liquidez comunicadas por los países).

- Una vez terminada la crisis sanitaria, las empresas se encontrarán en un contexto de recesión. Debido a que las ventas en gran parte de las actividades probablemente se recuperarán lentamente, la necesidad de liquidez podría extenderse y el cobro de las deudas contraídas en el momento de la crisis sanitaria podría inviabilizar las operaciones. Por esta razón, el plazo y la modalidad de pago de los créditos y las obligaciones postergadas son cruciales para que las empresas sigan operando. Las medidas para proveer liquidez y la extendida concesión de créditos siguen la lógica de considerar como presentes utilidades futuras. Esta lógica se 
fundamenta en el supuesto de que habrá utilidades futuras con las cuales pagar los créditos y los impuestos diferidos. Las perspectivas actuales no avalan la idea de que unos dos años sea un plazo suficiente para generar el flujo de utilidades necesario para afrontar esos compromisos.

- Las medidas de ayuda directa, que podrían ser más efectivas que la postergación de pagos o los créditos para evitar los cierres en el mediano plazo, se utilizaron en muchos países, pero con una muy baja asignación de recursos dirigidos a empresas o sectores muy vulnerables. En los países respecto de los que fue posible identificar el monto asociado a las medidas de ayuda directa, el porcentaje varió entre el $0,02 \%$ y el 0,22\% del PIB, con montos mucho menores que los anunciados para las medidas de crédito.

- Las herramientas más utilizadas son las transferencias monetarias, en forma de bonos o subsidios, o la reducción o eliminación de cargas impositivas (véase el gráfico 14). Las mipymes y los trabajadores independientes, las actividades vinculadas al turismo (como hoteles y servicios gastronómicos), las actividades culturales y el sector agropecuario se encuentran entre los beneficiarios más frecuentes de estas medidas.

Gráfico 14 | América Latina y el Caribe (22 países): ayuda directa a las empresas, según modalidad (En porcentajes del número de medidas)

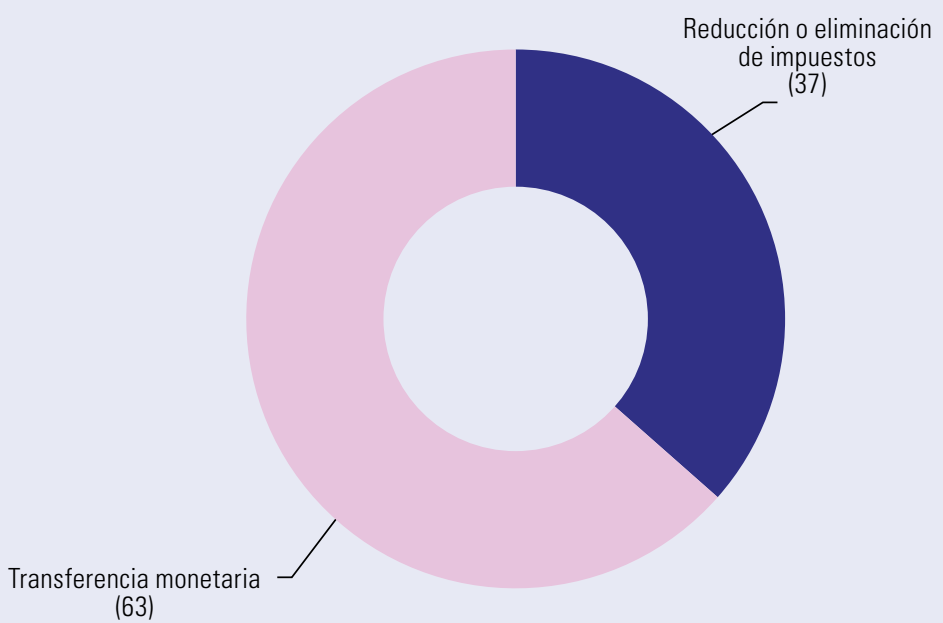

Fuente: Comisión Económica para América Latina y el Caribe (CEPAL), sobre la base de Observatorio COVID-19 en América Latina y el Caribe [en línea] https://www.cepal.org/es/temas/covid-19 e información oficial al 27 de mayo de 2020

- Otras medidas para evitar la destrucción de capacidades buscan impedir los despidos. En muchos países se flexibilizaron los vínculos laborales y, más recientemente, se ofrecieron subsidios para el pago de los salarios. Estos últimos se aplican durante la emergencia y cuando las empresas cumplen ciertas condiciones: por ejemplo, sufrir una caída significativa en las ventas en el período de emergencia, o pertenecer a ciertas actividades productivas que se vieron muy afectadas (véase el gráfico 15). En general, acogerse a estos beneficios implica que, pasado el período de gracia, los trabajadores deberán volver a sus tareas habituales por un período mínimo determinado, sin reducciones salariales. La flexibilización de las jornadas y los salarios, la suspensión de pagos previsionales y el adelanto de las vacaciones para quienes puedan acceder a este beneficio son también medidas muy extendidas.

- Las medidas directas para apoyar la producción fueron poco utilizadas. Los gobiernos reforzaron los presupuestos públicos de salud para fortalecer sus capacidades y adquirir insumos mediante el sistema de compra pública. En ocasiones, este mecanismo se flexibilizó para acelerar las adquisiciones a través del trato directo — sin mediar licitación-, a la vez que los gobiernos fijaron precios máximos para la compra de insumos. En Chile, se aceleró la implementación del portal Pago Oportuno (cuya prueba se había iniciado en el último trimestre de 2019). En sus primeras semanas de operación, se pagaron a través de este portal facturas pendientes del Estado central por un monto de más de 1.000 millones de dólares. 
Gráfico 15 | América Latina y el Caribe (18 países): medidas para evitar despidos (En porcentajes del número de medidas)

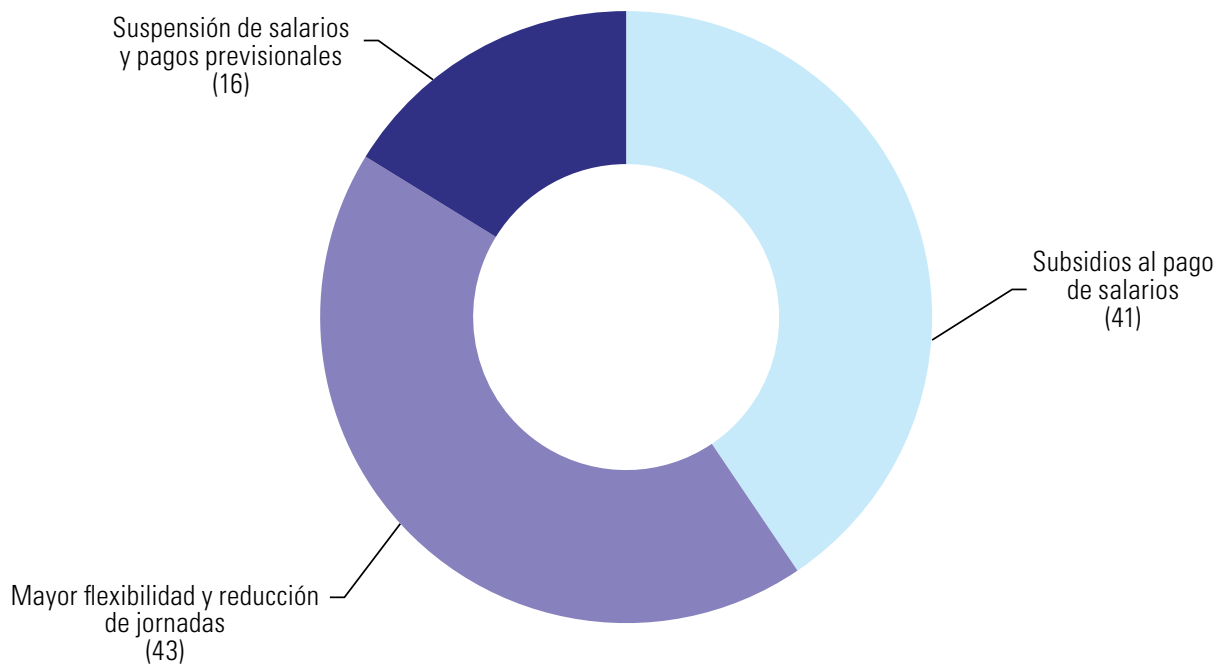

Fuente: Comisión Económica para América Latina y el Caribe (CEPAL), sobre la base de Observatorio COVID-19 en América Latina y el Caribe [en línea] https://www.cepal.org/es/temas/covid-19 e información oficial al 27 de mayo de 2020.

- Además de la compra pública, entre las escasas medidas de apoyo directo existen algunos programas para capacitar a las mipymes en materia digitalización o proveerles plataformas de venta en línea. Ello les permitiría adaptarse a la marcada reducción de las ventas presenciales.

- Solo cinco países adoptaron medidas específicas para apoyar a las empresas exportadoras. Entre ellas, destacan medidas tributarias como la aceleración del pago de reintegros o la postergación de pagos, así como la facilitación de algunas líneas de crédito para exportadores.

- Hasta finales de mayo no se habían observado medidas dirigidas exclusivamente a grandes empresas. Sin embargo, algunas de las medidas de corto y mediano plazo mencionadas, en particular las referidas al empleo, no discriminan por tamaño de empresa, lo que permite que la ayuda se dirija también a las grandes empresas. Asimismo, en algunas de las medidas de crédito se establecen criterios diferentes para las empresas de mayor tamaño.

- En Europa, el carácter estratégico de algunas empresas en términos de desarrollo tecnológico, militar o económico ha llevado a que algunos gobiernos adopten medidas de rescate de grandes empresas. Estas intervenciones a menudo son condicionadas a la suscripción de compromisos y su correspondiente cumplimiento. Por ejemplo, en Alemania se otorgará crédito a la empresa Adidas, condicionado a que no se repartan utilidades mientras el crédito esté vigente. En Dinamarca y Polonia, por su parte, no se otorgarán préstamos a empresas con sedes en paraísos fiscales.

- En 23 países de la región se adoptaron 91 medidas en las que se enfatiza la pertenencia a un sector para acceder a los beneficios. La mayor cantidad de medidas se dirigieron al sector del turismo y las mipymes agropecuarias y de alimentación, aunque hay diferencias geográficas en el tipo de medidas sectoriales implementadas o anunciadas (véase el gráfico 16). En América del Sur, se prefirió extender las facilidades para el acceso al crédito de los sectores más afectados. En Centroamérica, se adoptaron medidas de ayuda directa enfocadas en el turismo, la actividad agropecuaria y la alimentación, mientras que en México se ha optado por ampliar los presupuestos a programas ya existentes ligados a la agricultura, la cultura y las artes. En el Caribe, cuya economía depende mucho del turismo, las medidas de ayuda monetaria en forma de bonos, subsidios y suspensión de cobros se han focalizado en el sector hotelero. 
Gráfico 16 | América Latina y el Caribe (23 países): medidas con enfoque sectorial, según tipología y sector (En porcentajes del número de medidas)

A. Tipo de medidas

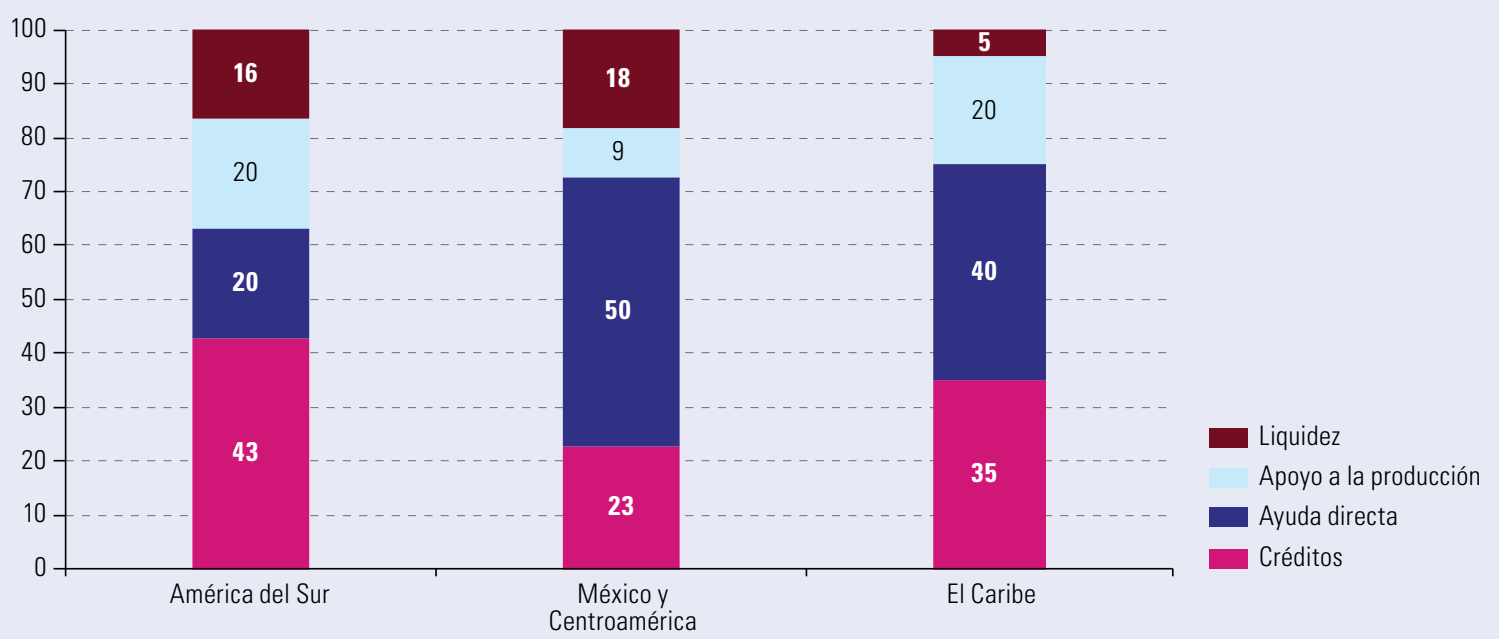

B. Sectores beneficiarios

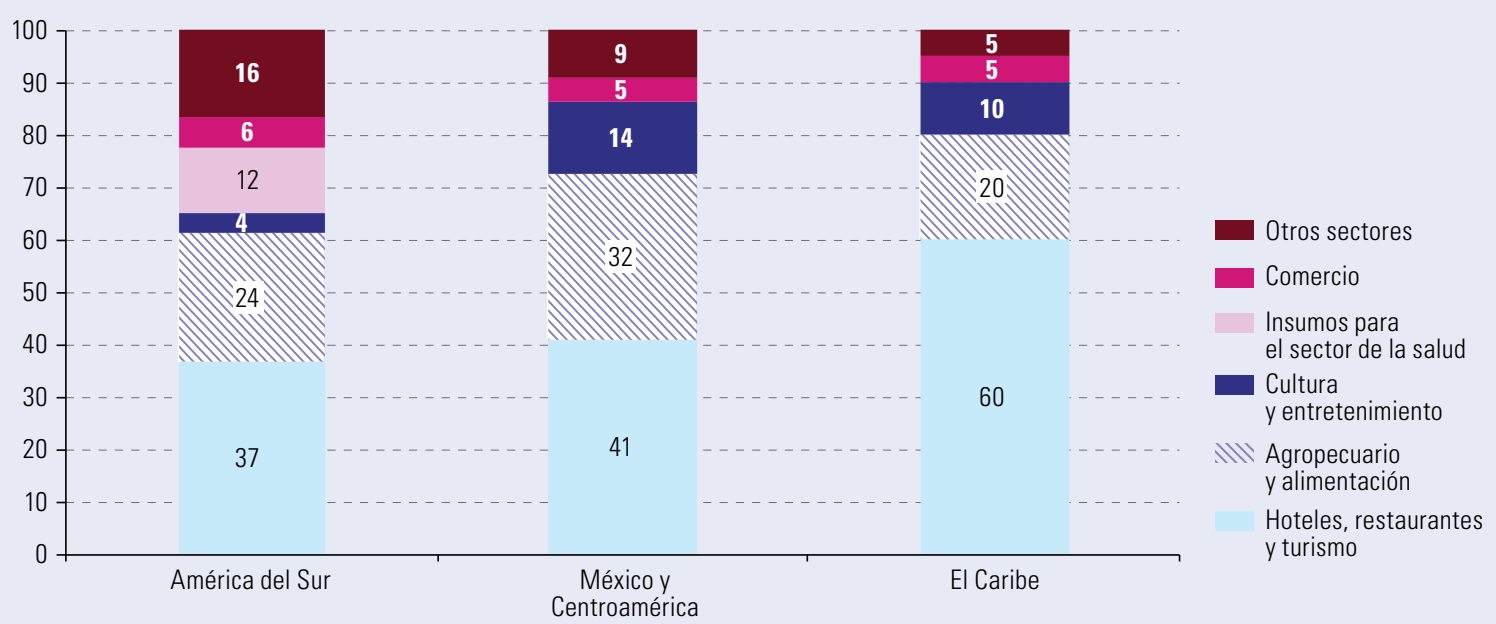

Fuente: Comisión Económica para América Latina y el Caribe (CEPAL), sobre la base de Observatorio COVID-19 en América Latina y el Caribe [en línea] https://www.cepal.org/es/temas/covid-19 e información oficial al 27 de mayo de 2020.

\section{F. El rol articulador de las cámaras empresariales}

- Las cámaras y asociaciones empresariales han desempeñado un rol clave durante la crisis, canalizando las inquietudes, demandas y propuestas del sector privado a las autoridades gubernamentales ${ }^{4}$. En algunos casos, se han establecido instancias para recibir las ofertas de colaboración del sector privado de manera centralizada y coordinarlas con las iniciativas a nivel ministerial o sectorial.

- Se han presentado propuestas en dos ámbitos. Por un lado, medidas específicas para reducir el impacto de la emergencia sanitaria en la actividad de las empresas y con ello evitar la destrucción de puestos de trabajo. Por otro, medidas que buscan la reactivación de las actividades económicas con el menor riesgo sanitario posible.

- En el primer ámbito, las asociaciones gremiales plantearon medidas para sostener la liquidez de las empresas, como diferir o exonerar el pago de impuestos y agilizar los pagos a los proveedores del Estado. Asimismo, para tener capacidad de pago en un momento en que los ingresos se ven muy disminuidos, las cámaras han propuesto mejorar el acceso al crédito de las empresas, principalmente de las pymes. En relación con esto último, han manifestado su preocupación por la efectividad y eficiencia de las medidas adoptadas ya que los recursos no

\footnotetext{
Se agradece a la Cámara de Industria, Comercio, Servicios y Turismo de Santa Cruz (CAINCO)(Estado Plurinacional de Bolivia), la Unión Industrial Argentina (UIA), la Asociación de Fábricas Argentinas de Componentes (AFAC), la Cámara de Industrias del Uruguay (CIU) y las cámaras de comercio de Colombia por la información y las perspectivas que han dado para este informe.
} 
llegan con la oportunidad y en las condiciones que requieren las empresas. En muchos casos, la liquidez otorgada por el gobierno y el banco central mediante transferencias y garantías no se canaliza adecuada y rápidamente desde las entidades financieras a las empresas.

- En el segundo ámbito, destacan los protocolos sanitarios para retomar actividades paralizadas. Con este propósito, las asociaciones empresariales han participado en instancias de diálogo con las autoridades gubernamentales sectoriales y locales. Algunos resultados preliminares se registran en los sectores de construcción, transporte y comercio y en numerosas actividades manufactureras y de servicios. En algunos casos, las propuestas de las cámaras han estado en conflicto con las decisiones gubernamentales respecto de la intensidad y extensión de las medidas de distanciamiento social, en especial las cuarentenas. Esto ha dificultado el diálogo público-privado sobre las medidas para enfrentar la pandemia.

- Desde el inicio de la emergencia, las cámaras acogieron las medidas restrictivas y promovieron entre sus asociados su cumplimiento para mantener, en la medida de lo posible, la continuidad de las actividades en condiciones de seguridad. Se han implementado modalidades de trabajo a distancia y jornadas laborales flexibles, y se han postergado eventos, suspendido viajes y apoyado la realización de actividades de sensibilización y difusión de información para la prevención de los contagios.

- Las cámaras también habilitaron servicios en línea y facilitaron el acceso a las medidas de política que afectan la actividad empresarial y su difusión. En muchos casos, se organizaron seminarios y capacitaciones gratuitas para las empresas.

- En varios países, para contribuir a mitigar los efectos de la crisis sanitaria, las cámaras han participado en campañas solidarias, aglutinando esfuerzos de los grandes grupos económicos, las empresas extranjeras, las empresas de menor tamaño y la sociedad civil. Estas campañas: i) apoyaron al sistema hospitalario con equipamiento médico — desde hospitales de emergencia a equipos de alta complejidad como ambulancias, monitores, respiradores mecánicos y equipos para tests de diagnóstico - e insumos de protección individual —alcohol en gel, mascarillas, guantes y delantales -; ii) atendieron a grupos vulnerables suministrándoles alimentos y artículos de higiene y protección, y iii) articularon iniciativas para fabricar equipos e insumos médicos.

- La pandemia puso de manifiesto las debilidades de los sistemas de salud y las cadenas de suministro de insumos clave. Sin embargo, también mostró la capacidad de adaptación de algunas empresas para suplir las debilidades de los sistemas productivos. Las iniciativas individuales y colectivas, en ocasiones articuladas por cámaras empresariales, instituciones públicas y centros académicos, permitieron adaptar la producción y proveer equipos, insumos y servicios esenciales al sistema de salud para enfrentar a la crisis sanitaria (véanse el diagrama 2 y cuadro 2).

Diagrama 2 | Escasez de productos esenciales durante la pandemia: estrategias nacionales y capacidades de adaptación

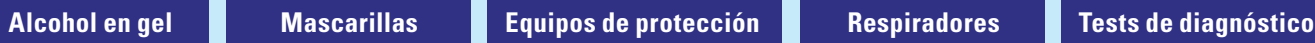

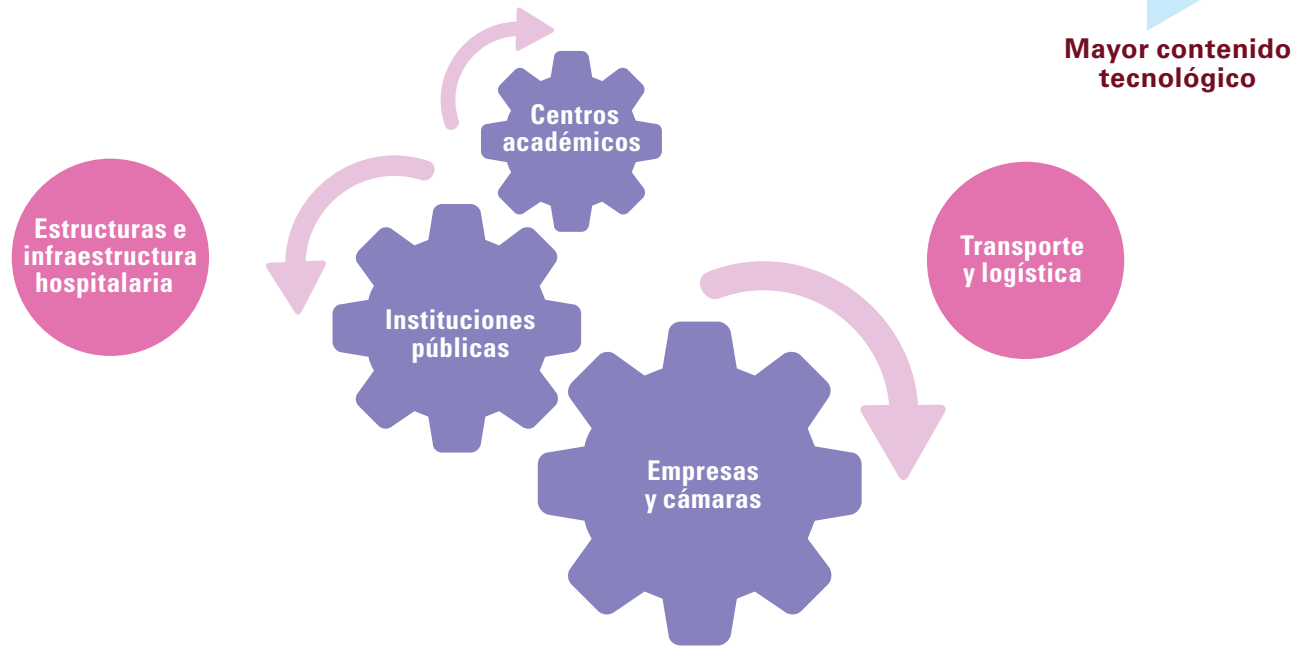


- Para enfrentar la crisis, las instituciones gubernamentales, las cámaras empresariales y los centros académicos han lanzado convocatorias para iniciativas de innovación. Estas incluyen desde financiamiento no reembolsable para proyectos que brinden soluciones a problemas asociados a la crisis sanitaria, hasta llamados para la fabricación de ventiladores mecánicos de emergencia (véase el cuadro 2).

Cuadro 2 I Iniciativas del sector productivo para apoyar al sistema sanitario y la salud de la población

\begin{tabular}{|c|c|c|c|}
\hline Producto & Industria & País & Ejemplo \\
\hline Alcohol en gel & $\begin{array}{l}\text { Fabricación de bebidas } \\
\text { alcohólicas, ingenios azucareros } \\
\text { y alcoholeros, fabricación de } \\
\text { cosméticos, fabricación de } \\
\text { pinturas, fabricación de productos } \\
\text { de limpieza, industria frigorífica, } \\
\text { laboratorios universitarios, } \\
\text { Fuerzas Armadas de la Argentina } \\
\text { y el Brasil }\end{array}$ & $\begin{array}{l}\text { Argentina, Brasil, } \\
\text { Chile, Colombia, } \\
\text { El Salvador, } \\
\text { Guatemala, } \\
\text { México }\end{array}$ & $\begin{array}{l}\text { - Grupos cerveceros nacionales } \\
\text { e internacionales utilizan el } \\
\text { alcohol que se obtiene como } \\
\text { subproducto del proceso } \\
\text { productivo de las cervezas } \\
\text { sin alcohol. } \\
\text { - Grupos cosméticos: L'Oreal en } \\
\text { la Argentina, Natura en el Brasil. }\end{array}$ \\
\hline Mascarillas & $\begin{array}{l}\text { Textil y de fabricación de papel } \\
\text { y cartón }\end{array}$ & $\begin{array}{l}\text { Argentina, Brasil, } \\
\text { Chile, Colombia, } \\
\text { Guatemala, } \\
\text { Haití, República } \\
\text { Dominicana }\end{array}$ & $\begin{array}{l}\text { - En Chile, Caffarena y Monarch, } \\
\text { fabricantes de calcetines, } \\
\text { medias y camisetas, producen } \\
\text { mascarillas con componente } \\
\text { de cobre. }\end{array}$ \\
\hline $\begin{array}{l}\text { Equipos de } \\
\text { protección para } \\
\text { profesionales de } \\
\text { la salud (como } \\
\text { máscaras y } \\
\text { escudos) }\end{array}$ & $\begin{array}{l}\text { Automotriz, fabricación de } \\
\text { electrodomésticos, industria del } \\
\text { plástico, impresión 3D en centros } \\
\text { tecnológicos y universidades, } \\
\text { fabricantes de maquinaria y equipo }\end{array}$ & $\begin{array}{l}\text { Argentina, Brasil, } \\
\text { Chile, Colombia, } \\
\text { Costa Rica, } \\
\text { Uruguay }\end{array}$ & $\begin{array}{l}\text { - En la Argentina, Ford, } \\
\text { Volkswagen, Mercedes-Benz } \\
\text { y Fiat Chrysler fabricaron } \\
\text { protectores faciales. } \\
\text { - En Chile, Comberplast, empresa } \\
\text { de productos plásticos, produce } \\
\text { máscaras y protectores faciales } \\
\text { con plástico reciclado. }\end{array}$ \\
\hline $\begin{array}{l}\text { Logística, } \\
\text { distribución y } \\
\text { transporte }\end{array}$ & $\begin{array}{l}\text { Aerolíneas, empresas de } \\
\text { autobuses, empresas tabacaleras, } \\
\text { industria automotriz, } \\
\text { industria cervecera }\end{array}$ & $\begin{array}{l}\text { Argentina, Brasil, } \\
\text { Chile, Colombia, } \\
\text { México, Panamá }\end{array}$ & $\begin{array}{l}\text { - En Colombia, la cervecera } \\
\text { Bavaria puso a disposición del } \\
\text { Gobierno su flota de camiones } \\
\text { y su experiencia logística para } \\
\text { transportar alimentos y otros } \\
\text { productos de primera necesidad. }\end{array}$ \\
\hline $\begin{array}{l}\text { Estructuras e } \\
\text { infraestructura } \\
\text { hospitalaria }\end{array}$ & $\begin{array}{l}\text { Construcción, industria } \\
\text { metalmecánica, metalúrgica, } \\
\text { industria hotelera, minería, } \\
\text { automotriz }\end{array}$ & $\begin{array}{l}\text { Argentina, Brasil, } \\
\text { Chile, Colombia, } \\
\text { México, República } \\
\text { Dominicana, } \\
\text { Uruguay }\end{array}$ & $\begin{array}{l}\text { - En Argentina, Fiat produjo camas, } \\
\text { y en el sector siderúrgico, Ternium } \\
\text { Argentina despachó a fines de } \\
\text { marzo más de } 270 \text { toneladas de } \\
\text { acero para la fabricación } \\
\text { de hospitales modulares. } \\
\text { - En la República Dominicana, la } \\
\text { Asociación de Hoteles y Turismo } \\
\text { de República Dominicana } \\
\text { (ASONAHORES) ofreció } \\
\text { 1.500 habitaciones como cuartos } \\
\text { de aislamiento para personas } \\
\text { infectadas con coronavirus. }\end{array}$ \\
\hline
\end{tabular}

Fuente: Comisión Económica para América Latina y el Caribe (CEPAL).

- En la medida que aumenta el número de contagiados, la disponibilidad de respiradores mecánicos se convierte en un elemento crítico para los sistemas de salud. Además de las iniciativas del sector privado para la compra y donación de respiradores, algunos gobiernos convocaron a las empresas a participar en programas para reparar y recuperar respiradores en desuso y, en el caso de tener capacidad de fabricación local, aumentar la producción de estos dispositivos.

- Frente a la emergencia, los Gobiernos de la Argentina y el Brasil han prohibido que las empresas fabricantes de respiradores hospitalarios los exporten, y las han impulsado a forjar alianzas estratégicas para aumentar su escala de producción. 
Cuadro 3 | Iniciativas colectivas para apoyar al sistema sanitario y la salud de la población

\begin{tabular}{lll}
\hline Producto & Industria & País \\
\hline Ventilador & Automotriz, & Argentina, \\
mecánico & universidades, & Brasil, Chile, \\
& alianzacon & Colombia, \\
& empresas & Costa Rica, \\
& delsector de & Guatemala, \\
& equipamiento & México, \\
& médico & Uruguay
\end{tabular}
Ejemplo

- En la Argentina, Toyota con la autopartista Mirgor y el Instituto Tecnológico de Buenos Aires (ITBA) producen un dispositivo de soporte respiratorio mecánico.

- En la Argentina, Mirgor tiene un contrato con Leistung, productora de ventiladores de Córdoba, para fabricar grandes cuantidades de estos aparatos en las plantas de Mirgor en Tierra del Fuego.

- En el Brasil, el Servicio Nacional de Aprendizaje Industrial (SENAI) implementó un programa con empresas del sector automotriz y metalúrgico para la recuperación de respiradores en desuso.

- En Colombia, existe una iniciativa colectiva de instituciones públicas y privadas, \#InnspiraMED, creada con el fin de aportar una solución para la producción de ventiladores mecánicos con recursos locales y de bajo costo. Los ventiladores están todavía en fase de prueba.

- En Chile, alrededor de 14 equipos están trabajando para lograr prototipos viables de ventiladores que se puedan replicar industrialmente.

- En Costa Rica, el proyecto "Respira UCR", liderado por la Universidad de Costa Rica (UCR) y la Caja Costarricense de Seguro Social (CCSS), ha desarrollado un prototipo de ventilador mecánico portátil.

- En Guatemala, se fabricó un ventilador mecánico portátil de bajo costo (VentiLab IG), que permite la ventilación continua del paciente, cuyas capacidades aumentan por medio de la actualización del software integrado.

- En México, el Tecnológico de Monterrey, el Instituto Nacional de Ciencias Médicas y Nutrición Salvador Zubirán y las empresas Femsa, Metalsa, Torey y Bocar, coordinados por la Secretaría de Relaciones Exteriores, fabricaron el primer ventilador mecánico en México en cinco semanas. Es un equipo de bajo costo que utiliza componentes y diseños disponibles en el país. La capacidad de producción es de 600 equipos por semana.

- En el Uruguay, un grupo de técnicos en informática ha desarrollado un respirador mecánico asequible, fácil de utilizar y sin patentes. La producción del ventilador Guenoa es económica y puede realizarse con componentes disponibles en el país. Su costo es menos de 27 dólares.

Test de diagnóstico de COVID-19
Institutos de investigación, centros tecnológicos, universidades, empresas de biotecnología

\section{Argentina,} Brasil, Colombia, Uruguay

- En la Argentina se desarrolló un kit de prueba mediante una alianza de instituciones privadas y públicas.

- En el Brasil, el Hospital Israelita Albert Einstein de São Paulo desarrolló el primer examen genético del mundo capaz de detectar el nuevo coronavirus mediante el uso de la tecnología de secuenciación de nueva generación sin presentar falsos negativos.

- En Colombia, Índigo Technologies desarrolló un algoritmo de inteligencia artificial que permite identificar casos positivos de COVID-19 en segundos.

- En el Uruguay, un acuerdo entre el Ministerio de Salud Pública، la Universidad de la República y el Instituto Pasteur de Montevideo permitió desarrollar un test para detectar casos positivos de coronavirus.

- En la Argentina, algunas pymes del sector textil se unieron para confeccionar más de 150.000 kits semanales (unos 750.000 mensuales) que incluyen camisolines, mascarillas y cofias, hechos con los moldes y especificaciones dados por el Gobierno.

- En Colombia, cuatro empresas unieron sus conocimientos y experiencia para crear un prototipo de estructura hospitalaria hecha en PVC y metal. infraestructura metalurgia,

hospitalaria artículos para el hogar 
Las iniciativas más exitosas de cooperación para la producción de insumos y equipos se dieron principalmente en economías con capacidades construidas durante sus procesos de industrialización. La acumulación de capacidades laborales y de gestión en el largo plazo ha sido un factor crucial en la capacidad de respuesta de empresas y sectores.

\section{G. Ante la difícil coyuntura empresarial, respuestas a gran escala}

- La recuperación será más lenta y gradual de lo inicialmente esperado y, pese a los programas puestos en marcha por los gobiernos, es esperable un alto nivel de destrucción de empresas y empleos. Cuanto mayor sea este efecto, mayor será la pérdida de capacidades acumuladas en las empresas, la dispersión de conocimientos y experiencias y la ruptura de relaciones de confianza entre los actores económicos.

\section{- Ante esta situación la CEPAL propone tres conjuntos de medidas:}

1. Ampliar los plazos y los alcances de las líneas de intervención en materia de liquidez y financiamiento para las empresas.

2. Reforzar las transferencias directas a las empresas para evitar la destrucción de capacidades.

3. Apoyar a las grandes empresas de sectores estratégicos que resulten gravemente afectadas por la crisis.

- El primer conjunto de medidas implica aumentar la liquidez de las empresas, principalmente las de menor tamaño, mediante:

- La postergación o cancelación de los pagos de impuestos, imposiciones previsionales y contribuciones territoriales, o el adelanto de las devoluciones de impuestos por lo menos hasta finales de 2020.

- La suspensión del pago de los servicios de luz, agua, gas y telecomunicaciones, sin multas ni corte de servicios, hasta finales de 2020.

- La flexibilización y mejora de las condiciones de crédito:

- Los períodos de gracia deben ser de por lo menos un año y los plazos de cinco años o más.

- Deben reforzarse las operaciones de crédito a través de la banca de desarrollo, que tiene una mayor propensión que la banca comercial a asumir el riesgo asociado a las empresas de menor tamaño.

- El segundo conjunto de medidas busca evitar la destrucción de capacidades:

- Cofinanciamiento de la nómina salarial diferenciando según el tamaño de las empresas: $30 \%$ para las grandes empresas, $50 \%$ para las medianas, $60 \%$ para las pequeñas y $80 \%$ para las microempresas. Este subsidio tendría una duración de seis meses y su costo se estima en un $2,7 \%$ del PIB (véase gráfico 17).

Gráfico 17 | Costo del cofinanciamiento de la nómina salarial por tamaño de empresas (En porcentajes del PIB)

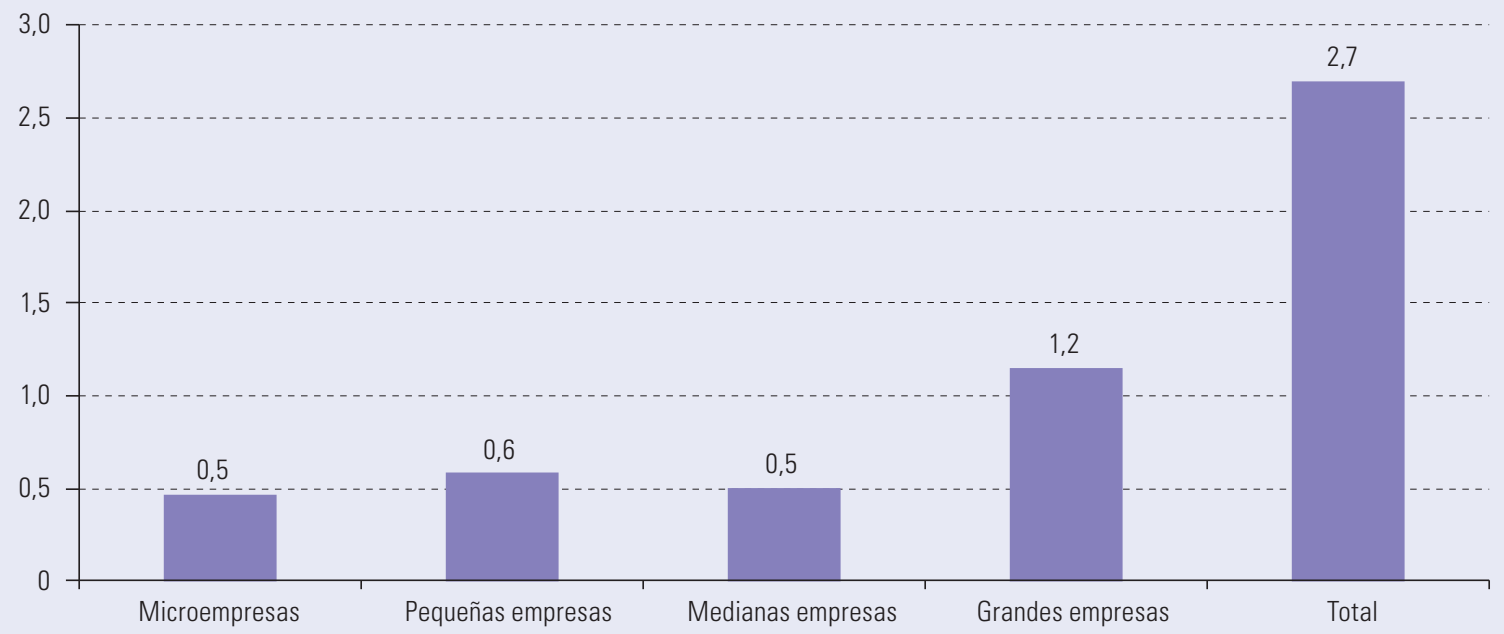

Fuente: Comisión Económica para América Latina y el Caribe (CEPAL), sobre la base de información oficial. 
- Una contribución en efectivo para los trabajadores autónomos formales ${ }^{5}$. Este subsidio por seis meses para cada trabajador autónomo podría llegar hasta 500 dólares según el poder adquisitivo en cada país. Los recursos públicos comprometidos a nivel regional representarían un $0,8 \%$ del PIB y alcanzarían a más de 15 millones de trabajadores.

Gráfico 18 | América Latina (7 países): costo de la contribución a los trabajadores autónomos (En porcentajes del PIB)

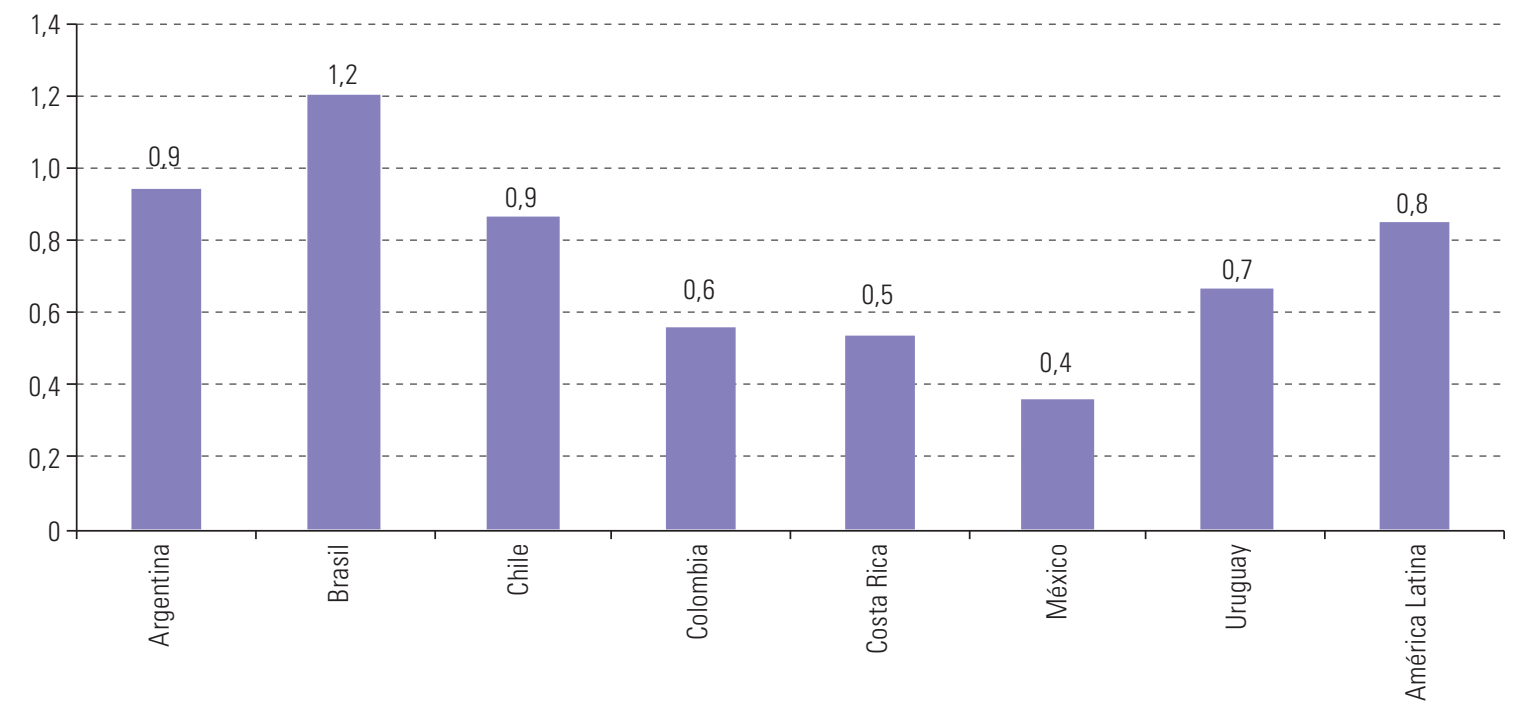

Fuente: Comisión Económica para América Latina y el Caribe (CEPAL), sobre la base de información oficial.

- Estas dos medidas complementan las propuestas de la CEPAL de establecer un ingreso básico de emergencia para toda la población en situación de pobreza en 2020 y un bono contra el hambre para la población en pobreza extrema, con un costo del $2,1 \%$ y el 0,6\% del PIB, respectivamente (véanse CEPAL (2020) y CEPAL/FAO (2020)). En la medida en que el cofinanciamiento de la nómina y el apoyo en efectivo a los trabajadores autónomos sean eficaces, disminuirán el desempleo y la pobreza, reduciéndose así el costo total del ingreso básico de emergencia y del bono contra el hambre. Existiría una sinergia entre las medidas de apoyo al empleo y la reactivación y las de atención inmediata a las situaciones personales y familiares más críticas.

- El tercer conjunto de medidas supone tomar en cuenta el rol y la importancia de las grandes empresas. Estas representan el 39\% del empleo formal y más del $90 \%$ de las exportaciones, su rol es protagónico en los sectores de mayor intensidad tecnológica y extremadamente relevante en la generación de cadenas de proveedores. Por ello su aporte al incremento de la productividad de los países es clave para garantizar el crecimiento, así como la transición hacia un modelo de desarrollo más sostenible.

- Aunque su capacidad de resiliencia es mayor en la fase de emergencia, en comparación con las empresas de menor tamaño, las pérdidas de empleo, capacidad productiva, tecnológica y exportadora son riesgos reales que pueden condicionar seriamente la fase de reactivación.

- Por estas razones, además del acceso al crédito en condiciones favorables y el cofinanciamiento de la nómina salarial, es necesario considerar la posibilidad de que el Estado participe en la recapitalización de grandes empresas de sectores estratégicos para el crecimiento del país. Estos apoyos deben estar condicionados a que estas empresas se comprometan a no despedir trabajadores por un plazo determinado desde la recepción del cofinanciamiento o de los aportes de capital, a no distribuir utilidades por un período similar y a implementar planes de inversión para acelerar la reactivación o aumentar la sostenibilidad ambiental de sus operaciones. Asimismo, las grandes empresas deben empeñarse en reducir los plazos de pago a sus pequeños proveedores, llegando posiblemente a pagos al contado.

Se incluyen aquí a los trabajadores por cuenta propia formales, los monotributistas y las microempresas unipersonales formales. 
- A fin de apoyar a grandes empresas viables con problemas de liquidez, se debe aumentar la eficacia del mercado de capitales para generar mecanismos de financiamiento más flexibles; por ejemplo, la emisión de bonos o bonos convertibles en acciones, que generalmente tienen un menor costo para el deudor. En momentos de gran incertidumbre es crucial la transparencia de los mercados, es decir que los inversores tengan acceso a información financiera sobre la empresa, con respecto, por ejemplo, a los niveles de precios, la profundidad del mercado y los informes financieros auditados. Por su parte, el fortalecimiento de los mecanismos de regulación permitiría a los reguladores monitorear si los niveles de capital y liquidez son los adecuados, así como la eficacia de la gestión del riesgo por los consejos de administración. El aumento de la transparencia y la mayor eficacia de la regulación pueden complementar las medidas de reactivación en tanto aumenten la confianza de los posibles inversores.

- En paralelo con las medidas mencionadas, debe garantizarse la seguridad de los empresarios, empleados, clientes y proveedores de las empresas. Para ello, es necesario implementar protocolos de seguridad para el funcionamiento de las empresas. A partir de lineamientos generales definidos por la autoridad sanitaria, y con la participación de las cámaras empresariales, los sindicatos y las autoridades gubernamentales, es preciso elaborar e implementar normas de conductas específicas para cada sector. Asimismo, la seguridad del transporte público (sanitización de los vehículos y de la infraestructura de apoyo, instalación de una separación para los conductores, distribución de desinfectante y mascarillas a los operadores de los servicios, entre otras medidas) es fundamental para que las empresas no tengan que recurrir a medios de transporte propios (y, por lo tanto, con mayores costos) para conseguir el desplazamiento seguro de sus empleados.

\section{H. De la emergencia a la reactivación: modificación} de la estructura productiva y la inserción internacional

- El impacto de la crisis se ve amplificado por la debilidad de la estructura productiva. Antes de la pandemia, la estructura productiva de la región presentaba una gran heterogeneidad estructural que limitaba seriamente las posibilidades de desarrollo económico. La pandemia hace más evidente estas debilidades y amplifica las tensiones económicas, sociales y ambientales. En el ámbito productivo, la coyuntura plantea la urgencia de mitigar la destrucción de las capacidades, sin olvidar la necesidad de aumentar de manera sostenida la productividad, generar encadenamientos productivos e incrementar el aprendizaje y la generación y difusión de innovaciones (la llamada eficiencia schumpeteriana).

- En este contexto, la industria adquiere una importancia estratégica y un rol protagónico en el proceso de crecimiento y en el cambio de la matriz productiva. Para ello, se requieren políticas para modificar la estructura productiva, es decir, incentivos distintos de los que prevalecen en la actualidad para que las empresas privadas, junto con el Estado, realicen las inversiones necesarias para diversificar la estructura económica, garantizar un proceso continuo y estable de crecimiento y evitar retrocesos sociales y ambientales.

- El regreso a la actividad y la reactivación de la economía producirán cambios importantes en las empresas y la organización de las cadenas productivas.

- En las empresas, la pandemia ha obligado a modificar las condiciones de seguridad para sus trabajadores, proveedores y clientes, así como la manera en que se relacionan entre sí. El distanciamiento social ha acelerado la transformación digital e impulsado procesos que buscan aumentos de la productividad y la eficiencia. En un entorno de cambios rápidos y marcada incertidumbre, muchas empresas se han visto obligadas a innovar, reevaluar la forma en que operan y cambiar sus modelos de negocio. Esto implica generar capacidades para identificar rápidamente los cambios en las preferencias de los consumidores y garantizar que la cadena de proveedores y los servicios ofrecidos sean consecuentes con esos cambios. Asimismo, significa incorporar la idea de que la "seguridad sanitaria" puede llegar a ser un factor importante para mejorar productos y servicios.

- Las medidas adoptadas por los países para enfrentar la emergencia sanitaria han llevado a un aumento del uso de tecnologías digitales por las empresas en su relación con los consumidores, 
los proveedores y los empleados, así como en la organización de los procesos de gestión interna. Muchos de estos cambios seguirán también después de la emergencia, en particular aquellos asociados al comportamiento de los consumidores.

- Las tecnologías digitales serán clave en el nuevo modelo de funcionamiento de las empresas. Esto ocurrirá, en primer lugar, en las operaciones de promoción, venta y entrega de bienes y servicios, y en la interacción con los proveedores. En segundo lugar, las empresas tendrán que incorporar capacidades para adquirir y procesar grandes cantidades de información o macrodatos (big data) para sus procesos de toma de decisiones (seguimiento y adaptación a los cambios en la demanda, pero también la redefinición de las cadenas de suministro). Finalmente, es razonable esperar una mayor incorporación de dispositivos de interconexión digital en los procesos productivos, así como una mayor utilización de la robótica para incrementar la eficiencia, sobre todo tomando en cuenta que las necesidades de seguridad sanitaria pueden llevar a emplear una menor cantidad de trabajadores en algunas fases de producción.

Diagrama 3 | Cambios en la organización y el funcionamiento de las empresas

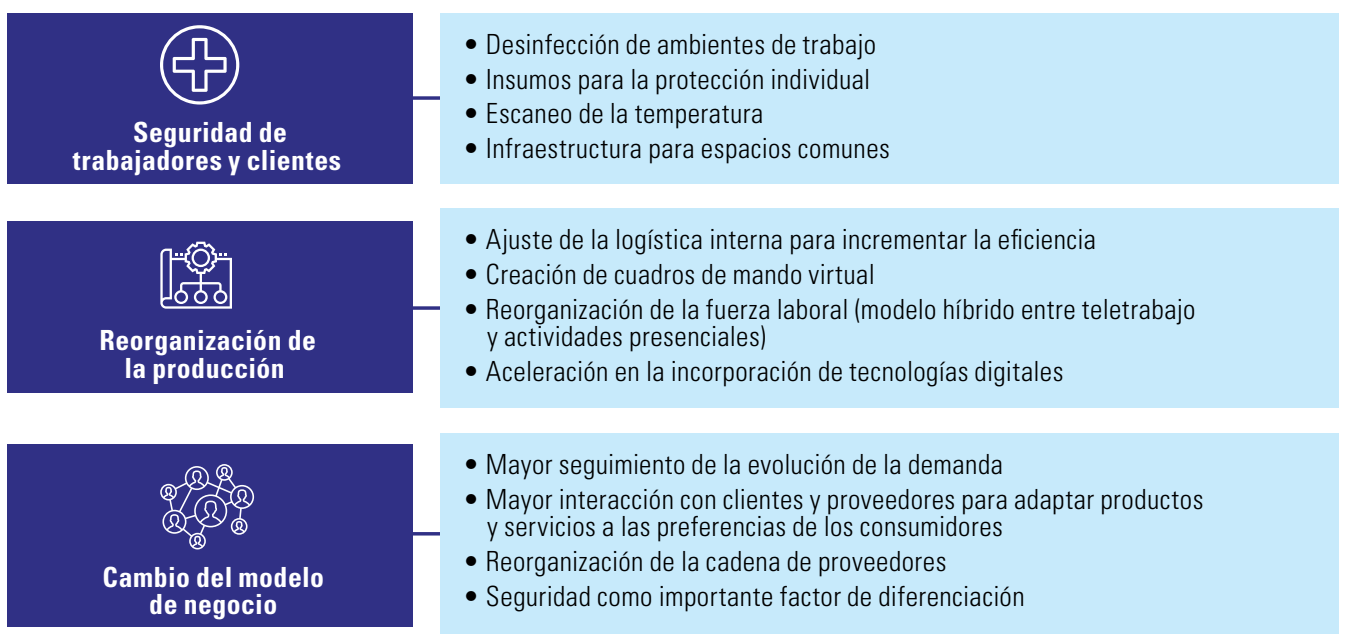

Fuente: Comisión Económica para América Latina y el Caribe (CEPAL).

- La adopción de protocolos de seguridad en las empresas supone un aumento de los costos. Las empresas tendrán que realizar inversiones para reorganizar los ambientes de trabajo, los espacios comunes (comedores y cafeterías, por ejemplo) y las instalaciones sanitarias. Además, es probable que deban mejorar y ampliar su dotación de equipos para el uso de tecnologías digitales a fin de implementar un modelo híbrido de teletrabajo y actividades presenciales. Estas inversiones llevarán a un aumento de los costos fijos. Al mismo tiempo, la mayor utilización de productos sanitarios y de limpieza implica mayores costos variables.

- La caída de la demanda interna e internacional generará, por lo menos en el mediano plazo, un aumento de la capacidad no utilizada, en comparación con la etapa previa a la crisis y, por lo tanto, incrementará los costos fijos por unidad producida.

- Para enfrentar esta situación, las empresas tendrán que avanzar en la búsqueda de mayor eficiencia y productividad. En ambos casos, el rol de las políticas es clave para generar los estímulos para que las empresas se orienten a los productos de mayor valor agregado, cambien el consumo de energía, tengan una mayor interacción entre sí (eficiencia colectiva) e incorporen nuevas tecnologías.

- Las cadenas de valor han sido un eje fundamental del proceso de globalización. Sin embargo, la crisis modificará la interdependencia de la economía mundial. Es probable que en la etapa de reactivación se rediseñen las modalidades de división internacional del trabajo.

- La crisis ha mostrado la fragilidad de la organización de la producción basada en cadenas de valor. Líneas de producción completas, en las que participa más de una economía, pueden detenerse debido a la falta de insumos, partes y componentes. Esto ha llevado al cuestionamiento de la gran dependencia de la industria de muchos países de la oferta de partes y componentes producidos en China. 
Diagrama 4 | La búsqueda de mayor productividad y eficiencia llevará a cambios en los productos y en la manera de producirlos

\section{Crisis}

Aumento de costos variables

Aumento de costos fijos

Menor producción
Respuesta dinámica

Mejorar la eficiencia

- Eficiencia energética

- Eficiencia colectiva

- Grandes datos

- Internet de las cosas

Productividad

- Productos de mayor valor agregado

- Aumento de la automatización
Modelo de transformación

productiva

sustentable

e inclusivo

Fuente: Comisión Económica para América Latina y el Caribe (CEPAL).

- El aumento del proteccionismo favorecería el traslado de las operaciones de las empresas a sus países de origen (reshoring) o a destinos cercanos (nearshoring). La alta concentración de producción en algunos países, por ejemplo, de fármacos e insumos médicos en China y la India, podría generar presiones por parte de los gobiernos de las economías desarrolladas para que sus empresas transnacionales aumenten su producción en sus países de origen.

- Las decisiones estratégicas en las cadenas globales del valor no dependerán exclusivamente de indicadores de rentabilidad, sino que resultará cada vez más importante la evaluación de aspectos relacionados con la garantía de abastecimiento de los insumos críticos, mientras que para los países adquirirá más relevancia la priorización de sectores estratégicos (salud, investigación médica, farmacéutico, biotecnológico).

- Los proveedores de las empresas transnacionales son los que enfrentan una mayor presión por las posibles rupturas de las redes internacionales de suministro. En este contexto, podrán generarse nuevas oportunidades asociadas con el desarrollo de capacidades nacionales y regionales.

- Las rupturas en las cadenas de suministro deberían llevar a valorizar a los productores locales, pero también a generar mecanismos de integración productiva regionales con el liderazgo de los países de la región con mayores capacidades industriales. Esto permitiría reforzar y expandir los mecanismos de integración productiva regional.

- En la medida en que la reactivación en el mediano plazo seguramente se base más en el aumento de la utilización de capacidad ociosa causada por la crisis que en inversiones (marcadamente deprimidas por la incertidumbre, la propia capacidad ociosa y el reducido espacio fiscal), la forma que adopte la reactivación determinará si los países de la región repetirán el camino que los condujo a la debilidad económica y social con que enfrentan la pandemia o sentarán los fundamentos de un cambio estructural progresivo.

- Por ello, es indispensable, ya en la etapa de reactivación, poner en marcha acciones para superar las debilidades estructurales de las economías de la región. En este sentido, la CEPAL ha propuesto una estrategia de gran impulso a la sostenibilidad que permitiría establecer una hoja de ruta con medidas para construir un nuevo modelo de desarrollo con igualdad y sostenibilidad.

- En el plano sectorial y empresarial, esto implica poner en marcha políticas industriales para el desarrollo de sectores que permitan realizar un cambio estructural hacia una mayor productividad e innovación, una mayor generación de empleos de calidad y una mayor sostenibilidad ambiental. 


\section{Bibliografía}

Agência IBGE Noticias (2020), "Indústria cai 18,8\% com pandemia em abril e tem pior resultado em 18 anos", 3 de junio, Instituto Brasileño de Geografia y Estatística (IBGE) [en línea] https://agenciadenoticias.ibge. gov.br/agencia-noticias/2012-agencia-de-noticias/noticias/27854-industria-cai-18-8-com-pandemia-emabril-e-tem-pior-resultado-em-18-anos.

CCIAP (Cámara de Comercio, Industrias y Agricultura de Panamá) (2020), “Resultados: III Encuesta: Impacto del Coronavirus en Panamá", mayo, inédito.

CEPAL (Comisión Económica para América latina y el Caribe) (2020), "El desafío social en tiempos del COVID-19", Informe Especial COVID-19, № 3, Santiago, 12 de mayo.

(2010), La hora de la igualdad: brechas por cerrar, caminos por abrir (LC/G.2432(SES.33/3)), Santiago.

CEPAL/FAO (Comisión Económica para América latina y el Caribe/Organización de las Naciones Unidas para la Alimentación y la Agricultura) (2020), "Cómo evitar que la crisis del COVID-19 se transforme en una crisis alimentaria: acciones urgentes contra el hambre en América Latina y el Caribe", Informe COVID-19. CEPAL-FAO, Santiago.

CNC (Cámara Nacional de Comercio, Servicios y Turismo de Chile) (2020), "Resultados cuarta Encuesta Empresa ante el COVID19", 29 de mayo [en línea] https://www.cnc.cl/wp-content/uploads/2020/06/ Resultados-Cuarta-Encuesta-Empresa-ante-COVID19-Mayo-1.pdf.

CNCS (Cámara Nacional de Comercio y Servicios del Uruguay) (2020), Impacto económico del COVID-19, segunda edición, abril [en línea] https://www.cncs.com.uy/admin/uploads/estatico/lnforme\%20 Encuesta\%20COVID\%2019\%20I\%20Segunda\%20Edici\%C3\%B3n.pdf.

CNI (Confederación Nacional de la Industria) (2020), "Impactos da COVID-19 na indústria", Sondagem Especial, $\mathrm{N}^{\circ} 77,14$ de mayo.

CONFECAMARAS (Confederación Colombiana de Cámaras de Comercio) (2020), "Encuesta de las Cámaras de Comercio sobre el Impacto del COVID-19 sobre las empresas colombianas", 24 de abril [en línea] http://www.confecamaras.org.co/phocadownload/2020/Encuesta\%20C\%C3\%A1 maras\%20 de\%20Comercio\%20consolidada.pdf.

Dini, M. y G. Stumpo (coords.) (2019), “Mipymes en América Latina: un frágil desempeño y nuevos desafíos para las políticas de fomento. Síntesis", Documentos de Proyectos (LC/TS.2019/20), Santiago, Comisión Económica para América Latina y el Caribe (CEPAL).

FECAMCO (Federación de Cámaras de Comercio del Istmo Centroamericano) (2020), "Resultados encuesta \#2: 'Crisis del Coronavirus en Centroamérica'," 11 de mayo [en línea] https://www.panacamara.com/wpcontent/uploads/2020/05/200511-PPT-Encuesta-2-VP-Crisis-del-Coronavirus-en-Centroam\%C3\%A9rica.pdf.

INEGI (Instituto Nacional de Estadística y Geografía) (2020), "Indicadores del sector manufacturero cifras durante abril de 2020 (cifras desestacionalizadas)", Comunicado de Prensa, № 274/20, 18 de junio [en línea] https://www.inegi.org.mx/contenidos/saladeprensa/boletines/2020/emim/emim2020_06.pdf.

Katz, J. y G. Stumpo (2001), "Regímenes sectoriales, productividad y competitividad internacional”, Revista de la CEPAL, No 75 (LC/G.2150-P), Comisión Económica para América Latina y el Caribe (CEPAL), Santiago, diciembre.

UIA (Unión Industrial Argentina) (2020), "Informe especial: impacto del Covid en empresas II", Centro de Estudios (CEU), mayo [en línea] https://drive.google.com/file/d/1DE5ds3qWC6ZtWf8Ax7LechvfAW6IJ G4C/view. 


\section{Anexo}

Cuadro A1 | América Latina y el Caribe (27 países): medidas de apoyo al sector empresarial anunciadas por los gobiernos nacionales identificadas en los países seleccionados

(En número de medidas)

\begin{tabular}{|c|c|c|c|c|c|c|c|c|}
\hline País & Liquidez & Crédito & $\begin{array}{c}\text { Ayuda } \\
\text { directa }\end{array}$ & $\begin{array}{c}\text { Apoyo a la } \\
\text { producción }\end{array}$ & Empleo & Exportaciones & Total & $\begin{array}{l}\text { Enfoque } \\
\text { sectorial }\end{array}$ \\
\hline \multicolumn{9}{|l|}{ América del Sur } \\
\hline Argentina & 11 & 9 & 9 & 2 & 4 & 2 & 37 & 7 \\
\hline Bolivia(Estado Plurinacional de) & 5 & 3 & $\ldots$ & $\ldots$ & $\ldots$ & $\ldots$ & 8 & $\ldots$ \\
\hline Brasil & 17 & 17 & 1 & 2 & 3 & 1 & 41 & 9 \\
\hline Chile & 10 & 9 & 6 & 4 & 3 & $\ldots$ & 32 & 2 \\
\hline Colombia & 7 & 11 & 2 & 4 & 3 & $\ldots$ & 27 & 13 \\
\hline Ecuador & 4 & 3 & 1 & $\ldots$ & 1 & 1 & 10 & 3 \\
\hline Paraguay & 4 & 5 & 1 & 1 & 4 & $\ldots$ & 15 & 3 \\
\hline Perú & 3 & 4 & 5 & 2 & 2 & 1 & 17 & 8 \\
\hline Uruguay & 4 & 5 & 2 & $\ldots$ & 2 & $\ldots$ & 13 & 2 \\
\hline Venezuela(República Bolivariana de) & 1 & 2 & 3 & 1 & 1 & $\ldots$ & 8 & 2 \\
\hline México & 1 & 3 & 5 & $\ldots$ & $\ldots$ & $\ldots$ & 9 & 4 \\
\hline \multicolumn{9}{|l|}{ Centroamérica } \\
\hline Costa Rica & 6 & 3 & 3 & 3 & 2 & $\ldots$ & 17 & 4 \\
\hline El Salvador & 2 & 3 & 2 & $\ldots$ & 1 & $\ldots$ & 8 & 3 \\
\hline Guatemala & 4 & 3 & 2 & $\ldots$ & $\ldots$ & 1 & 10 & 1 \\
\hline Honduras & 4 & 8 & 4 & $\ldots$ & 1 & $\ldots$ & 17 & 8 \\
\hline Nicaragua & $\ldots$ & $\ldots$ & $\ldots$ & $\ldots$ & 2 & $\ldots$ & 2 & $\ldots$ \\
\hline Panamá & 6 & 3 & 4 & $\ldots$ & 3 & $\ldots$ & 16 & 2 \\
\hline \multicolumn{9}{|l|}{ El Caribe } \\
\hline Bahamas & 2 & 1 & 1 & $\ldots$ & $\ldots$ & $\ldots$ & 4 & 1 \\
\hline Barbados & $\ldots$ & 4 & 1 & $\ldots$ & 1 & $\ldots$ & 6 & 3 \\
\hline Belice & $\ldots$ & 2 & $\ldots$ & $\ldots$ & 1 & $\ldots$ & 3 & 2 \\
\hline Cuba & 4 & $\ldots$ & 5 & 1 & 1 & $\ldots$ & 11 & 4 \\
\hline Granada & 1 & 2 & 1 & $\ldots$ & $\ldots$ & $\ldots$ & 4 & 2 \\
\hline Haití & 4 & $\ldots$ & 1 & $\ldots$ & $\ldots$ & $\ldots$ & 5 & $\ldots$ \\
\hline Jamaica & 1 & $\ldots$ & 2 & 1 & $\ldots$ & $\ldots$ & 4 & 2 \\
\hline República Dominicana & 6 & 5 & $\ldots$ & 1 & 2 & $\ldots$ & 14 & 2 \\
\hline Santa Lucía & 1 & $\ldots$ & $\ldots$ & $\ldots$ & $\ldots$ & $\ldots$ & 1 & $\ldots$ \\
\hline Trinidad y Tabago & 2 & 7 & 2 & 1 & $\ldots$ & $\ldots$ & 12 & 4 \\
\hline Total & 110 & 112 & 63 & 23 & 37 & 6 & 351 & 91 \\
\hline
\end{tabular}

Fuente: Comisión Económica para América Latina y el Caribe (CEPAL), sobre la base de Observatorio COVID-19 en América Latina y el Caribe [en línea] https://www.cepal.org/es/temas/covid-19 e información oficial al 27 de mayo de 2020.

Nota: Los tres puntos se emplean para indicar los casos en que no se identificaron medidas clasificables en estas categorías; no se incluyen las medidas anunciadas por los gobiernos subnacionales; este cuadro no comprende una revisión exhaustiva de las medidas adoptadas en los países de la región y la información corresponde a las medidas que fueron identificadas en las fuentes consultadas hasta el 27 de mayo de 2020.

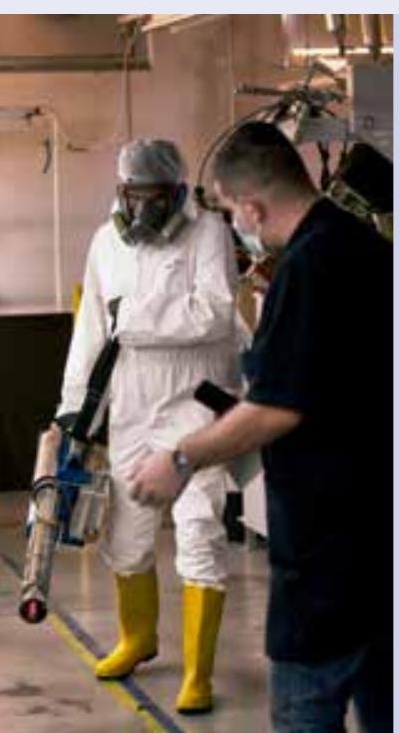

Este Informe Especial es el cuarto de una serie que elabora la Comisión Económica para América Latina y el Caribe (CEPAL) sobre la evolución y los efectos de la pandemia del COVID-19 en América Latina y el Caribe. Sus análisis económicos y sociales se actualizarán a medida que surja información relevante. La Secretaria Ejecutiva de la CEPAL, Alicia Bárcena, dirige la elaboración de este Informe, con el apoyo técnico de la Oficina del Secretario Ejecutivo Adjunto, Mario Cimoli, las Divisiones sustantivas encargadas de los temas que aquí se tratan, y las sedes subregionales y oficinas nacionales de la CEPAL.

Copyright $(\subset)$ Naciones Unidas, 2020 